\title{
A Comprehensive, Three-Dimensional Analysis of a Large-Scale, Multi-Fuel, CFB Boiler Burning Coal and Syngas. Part 2. Numerical Simulations of Coal and Syngas Co-Combustion
}

\author{
Jaroslaw Krzywanski ${ }^{1, * \mathbb{C}}$, Karol Sztekler ${ }^{2}{ }^{\mathbb{C}}$, Mateusz Szubel ${ }^{2}$, Tomasz Siwek ${ }^{2}$, \\ Wojciech Nowak ${ }^{2}$ and Lukasz Mika ${ }^{2}$ (D) \\ 1 Faculty of Science and Technology, Jan Dlugosz University in Czestochowa, al.Armii Krajowej 13/15, \\ 42-200 Czestochowa, Poland \\ 2 Faculty of Energy and Fuels, AGH University of Science and Technology, al. Mickiewicza 30, 30-059 Krakow, \\ Poland; sztekler@agh.edu.pl (K.S.); mzubel@agh.edu.pl (M.S.); siwek@agh.edu.pl (T.S.); \\ wnowak@agh.edu.pl (W.N.); lmika@agh.edu.pl (Ł.M.) \\ * Correspondence: j.krzywanski@ujd.edu.pl; Tel./Fax: +48-34-3615970
}

Received: 29 June 2020; Accepted: 28 July 2020; Published: 31 July 2020

\begin{abstract}
This paper presents the results of numerical computations for a large-scale OFz-425 CFB (circulating fluidized bed) boiler utilizing coal and syngas. Four different operating scenarios are considered, including the reference variant, corresponding to the conventional, mono-combustion of bituminous coal, and three tests involving replacement of secondary air and part of the coal stream with syngas fed by start-up burners. Pressure, gas velocity, temperature, and carbon dioxide distribution in the combustion chamber are discussed in the paper. The results indicate that the syngas supply leads to an increase in local temperature and carbon dioxide concentrations. The proposed concept is not advisable as it may lead to frequent emergency stops of the CFB boiler.
\end{abstract}

Keywords: circulating fluidized bed; CFD; multi-fuels boilers; modeling; simulation; co-combustion

\section{Introduction}

The performance of engineering devices is degraded by the presence of irreversibilities, and entropy generation constitutes their measure [1]. Since entropy generation is used for establishing criteria for the performance of engineering devices, the irreversibilities associated with a process should be reduced in order to increase engine performance [1,2]. Analysis and optimization via modeling can lead to an increase in a system's performance [2-4]. Computational fluid dynamics (CFD) models are considered to be the most comprehensive due to 3D, detailed consideration of chemical kinetics and individual physical processes, gas and solids continuity formulas, as well as momentum balances, and appropriate constitutive equations [5]. The CFD models can be used for complex analysis of multi-fuel CFB (circulating fluidized bed) unit operation concepts [6-9]. Various 3D-CFB models can be found in the literature [10-15], some of which consider the multi-fuel, CFB concept; however, the use of gaseous fuel, with a properly organized gas supply system, cannot be found in said literature. Such an idea may be beneficial for a power unit's flexibility and provides the stable operation of a boiler furnace with a substantial demand reduction in its capacity.

On the other hand, acceptable boiler design parameters may be exceeded due to changes in flue gas velocity and temperature profiles. Such cases may result in the destruction of some boiler components or a reduction in their service life [16-19]. 
The generated CFD model described in Part I of this paper was applied to study the influence of multi-fuel coal and syngas combustion on some operation issues of the large scale OFz-425 CFB boiler.

To the best of our knowledge, there are no reports in pertinent literature regarding comprehensive 3D-CFD modeling of a large-scale, multi-fuel, CFB boiler, burning coal and syngas.

\section{Materials and Methods}

The model was developed in the ANSYS Workbench environment for Fluent Solver. The two-phase, 3D model of homogenous and heterogeneous combustion employs CFD methods for the flow of a reactive mixture. The equations for mass, enthalpy, momentum, and selected gaseous components relevant to the combustion process were applied using the finite volume method. Reynolds-averaged Navier-Stokes equations (RANS) with the k-omega BSL turbulence model were used in the study. The heat transfer between the bed and the combustion chamber walls was considered using convection and radiation models.

Computations and validation of the model were successfully performed on data from an existing, large-scale, two-pass OFz- 425 CFB boiler at $100 \%$ load, produced by RAFAKO S.A., Poland. The main parts of the boiler are the riser with the combustion chamber made of membrane-walls, superheater II (SH II), reheater II (RH II), cyclones, and the second pass in the convection cage, consisting of built-in superheaters and reheaters, as well as an economizer and a rotary air heater.

The dimensions of the cross-sectional area of the combustion chamber in its lower part, immediately above the grid, are $4.6 \mathrm{~m} \times 11.6 \mathrm{~m}$ and $8.6 \mathrm{~m} \times 11.6 \mathrm{~m}$, at the height of $6.5 \mathrm{~m}$ above the gas distributor level. The total height of the combustion chamber is $37.2 \mathrm{~m}$. Two outlet windows, each with a dimension of $5.7 \mathrm{~m} \times 2.0 \mathrm{~m}$, are located in the upper part of the furnace at a level of $38 \mathrm{~m}$.

Four different operating scenarios were considered in this study. The first (Variant K0) was the reference case, which corresponded to the conventional mono-combustion of bituminous coal. The other three tests corresponded to cases with the replacement of secondary air and part of the coal stream with syngas, fed by start-up burners, as follows:

1. Variant K1 corresponds to the use of Nozzle No. 1, with a total $4.6 \mathrm{~kg} / \mathrm{s}$ of syngas supplied through two side, start-up burners,

2. Variant K2 considers the simultaneous use of Nozzles No. 1 and No. 2, with a total of $9.2 \mathrm{~kg} / \mathrm{s}$ of syngas supplied to the combustion chamber through four side, start-up burners, and

3. Variant K3 matches the simultaneous use of Nozzles No's. 1, 2 and 3, with a total of $13.8 \mathrm{~kg} / \mathrm{s}$ of syngas supplied to the combustion chamber through four side and two front, start-up burners.

A detailed description of the methodology used in this study can be found in Part I.

\section{Results}

\subsection{Validation}

Various methods available within the ANSYS CFD-Post post-processor module are used to conduct the calculations. Selected sections were generated in two perpendicular planes: $\mathrm{X}-\mathrm{Y}$ and $\mathrm{Y}-\mathrm{Z}$ (Figure 1). The results are presented in cuts, as follows:

1. Sectional view $X-Y$ parallel to the model's plane of symmetry, cut $X-Y-1,1.2 \mathrm{~m}$ away from the plane of symmetry, then subsequent cuts every $1 \mathrm{~m}$,

2. Sectional view $Y-Z$ parallel to the front/rear wall of the boiler, cut $Y-Z-11.26 \mathrm{~m}$ away from the front wall, then cuts arranged accordingly: $1.76 \mathrm{~m} ; 4.26 \mathrm{~m}$ (at equal distance from the front and rear wall), $6.76 \mathrm{~m}$ and $7.26 \mathrm{~m}$ from the front wall.

Pressure, velocity, temperature, and $\mathrm{CO}_{2}$ concentration profiles in the combustion chamber are discussed in the paper. The results are depicted successively for all considered variants of a given cut. 

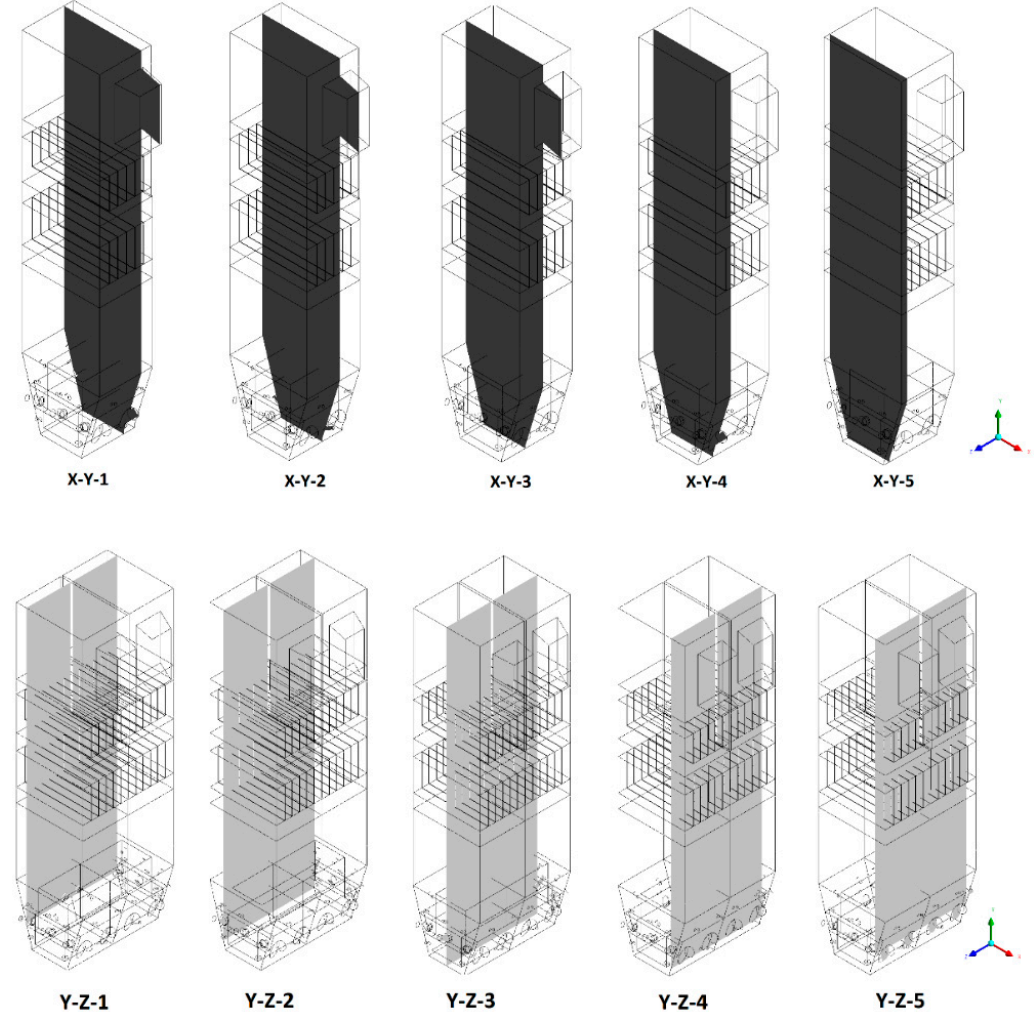

Figure 1. Visualization of sectional views used in the study.

Calculations by model and accessible experimental pressures and temperatures are compared in Tables 1 and 2. Based on measured data, it can be stated that high predictive accuracy was achieved by the model. The maximum relative error is below $7 \%$.

Table 1. Comparison of measured and calculated temperatures.

\begin{tabular}{cccc}
\hline Height above the Grid $\mathbf{m}$ & Measured Temperature ${ }^{\circ} \mathbf{C}$ & Calculated Temperature ${ }^{\circ} \mathbf{C}$ & Relative Error $\%$ \\
\hline 0.2 & 834.1 & 859.1 & -3.0 \\
1.2 & 817.3 & 830.2 & -1.6 \\
6.0 & 779.2 & 795.9 & -2.1 \\
\hline
\end{tabular}

Table 2. Comparison of measured and calculated pressures.

\begin{tabular}{cccc}
\hline Height above the Grid $\mathbf{m}$ & Measured Pressure kPa & Calculated Pressure kPa & Relative Error \% \\
\hline 0.2 & 7.03 & 7.38 & -4.99 \\
1.2 & 2.57 & 2.70 & -5.06 \\
6.0 & 0.32 & 0.34 & -6.25 \\
\hline
\end{tabular}

Such performed CFD models are used for further calculations. As the measured data are mostly confidential, the paper shows a limited number of measuring points located in the lower part of the combustion chamber (Tables 1 and 2).

However, because they were all located in the most computationally demanding, dense fluidized bed zone, which is additionally the main focus in the present study, the reported error shows the high accuracy of the CFD model [20].

\subsection{Pressure Distribution in the Combustion Chamber}

Figures 2 and 3 show pressure distribution in the X-Y-3 section. Some discrepancies can be found in the lower part of the wind box. Experimental data indicated a pressure $\sim 2.7 \mathrm{kPa}$ at a height of $1.2 \mathrm{~m}$, 
while a calculated value, averaged over the cross-sectional domain area, was $\sim 1.4 \mathrm{kPa}$. This discrepancy results from the simplifications made for the primary air inlet, which were beneficial for shortening the computational time.

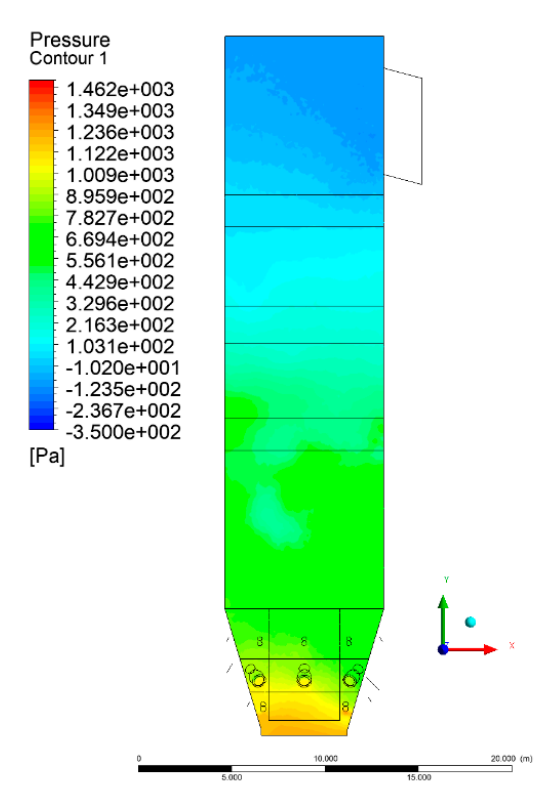

(a)

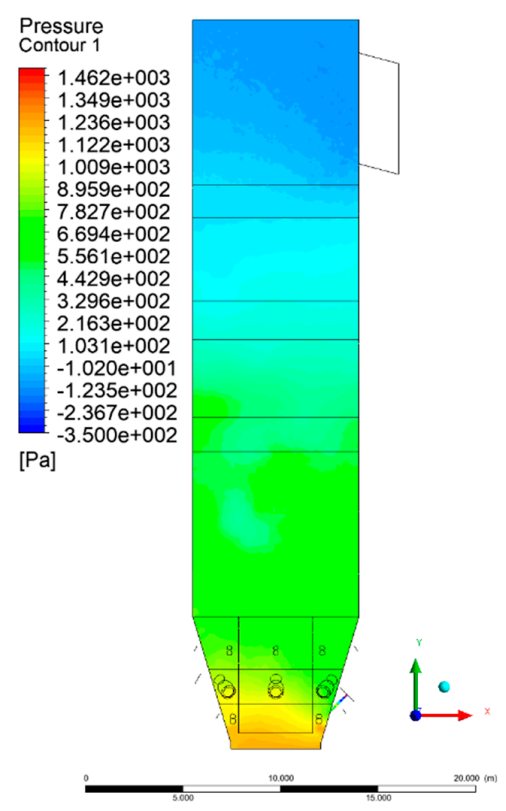

(b)

Figure 2. Pressure distribution, sectional view X-Y-3, variants K0 (a) and K1 (b).

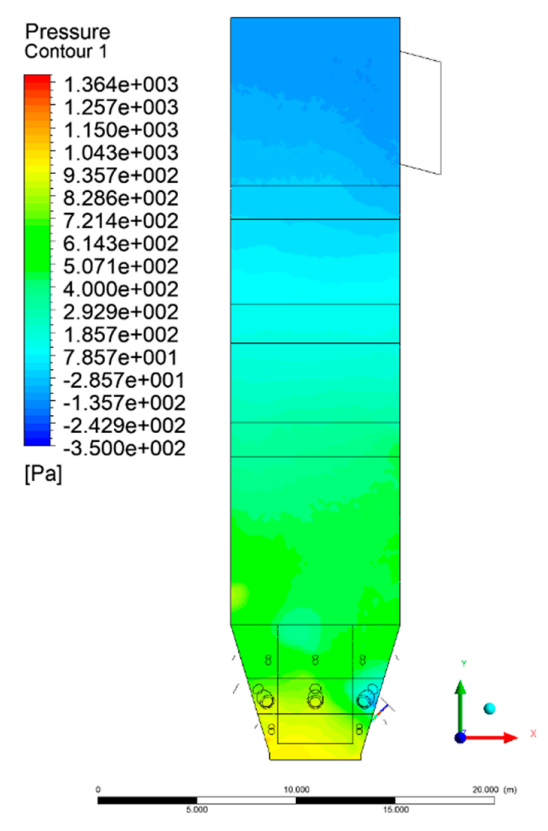

(a)

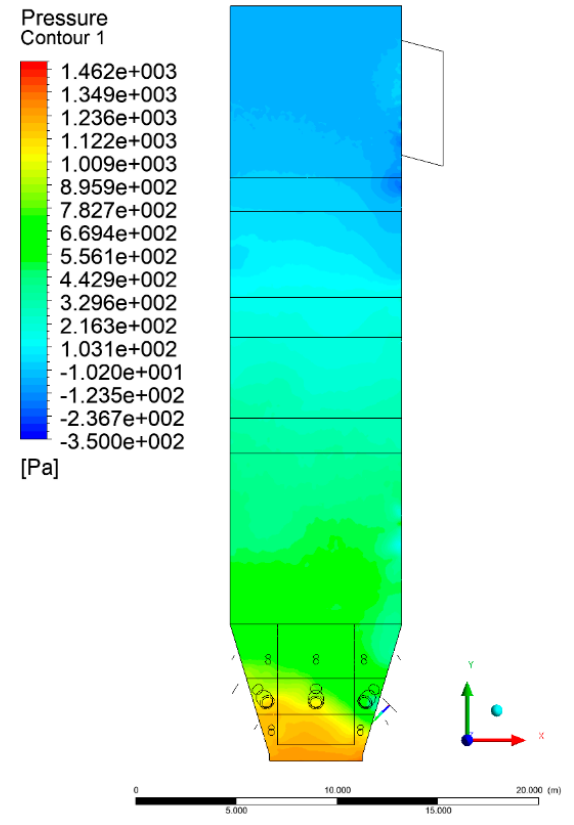

(b)

Figure 3. Pressure distribution, sectional view X-Y-3, variants K2 (a), K3 (b).

It should be noted that the boundary condition for the primary air inlet as the mass flow source was assumed, corresponding to a uniform mass flow over the whole cross-sectional area. The assumed uniform particle size distribution of inert material and fuel also influenced the obtained results. In the upper part of the riser (level $6 \mathrm{~m}$ and above), clear analogies to the experimental data can be found. At level $6 \mathrm{~m}$, the pressure averaged over the cross-sectional area was equal to $682 \mathrm{~Pa}$. 
The situation is also similar in the case of the exit zone of the combustion chamber, where, analogously to the experiment, negative pressures from -130 to $-350 \mathrm{~Pa}$ are registered. Again, it should be emphasized that due to the simplified approach, there is a homogeneous pressure field on the outlet surface of the computational domain. As expected, pressure distribution differed slightly, depending on the considered variant, which was visible on Y-Z sectional views (Figures 4 and 5). These differences are related to the defined syngas properties supplied to the furnace, as well as the applied radiation model, assuming the absorption of radiation by gas components (carbon dioxide, water vapor, methane).

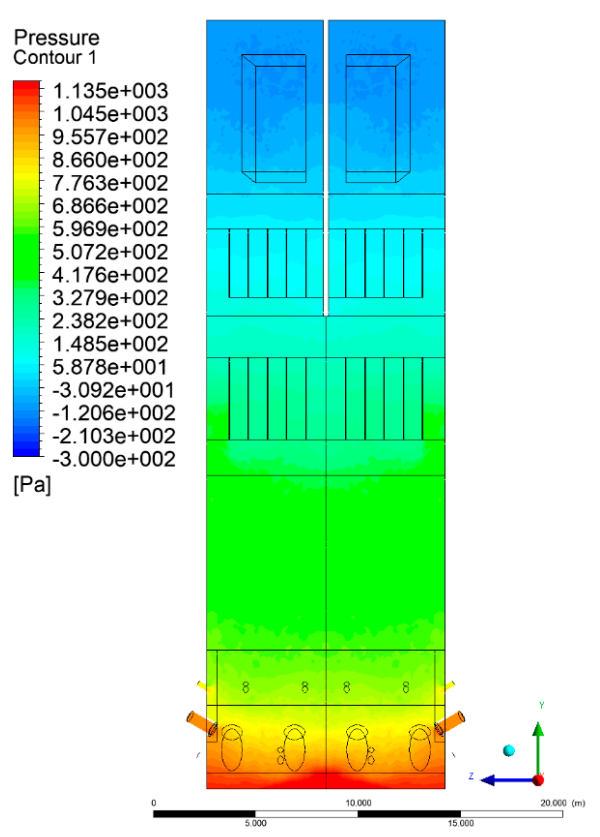

(a)

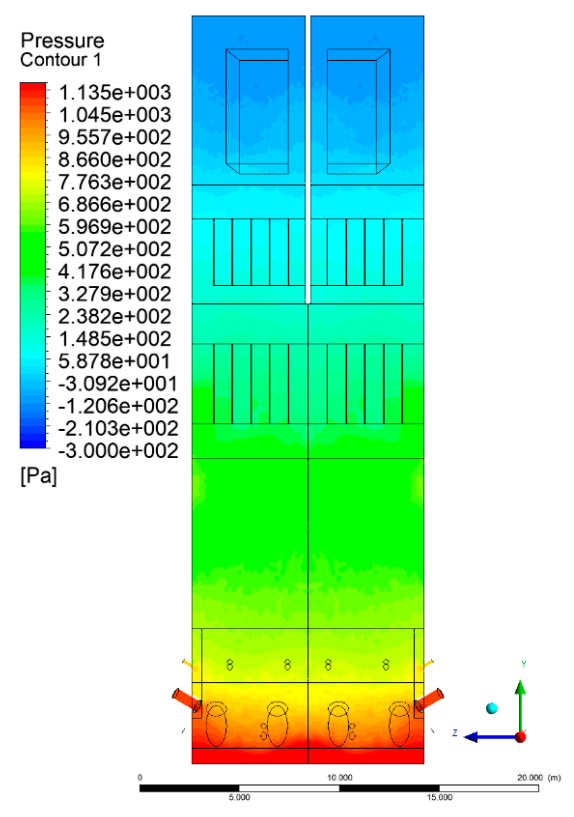

(b)

Figure 4. Pressure distribution, sectional view Y-Z-3, variants K0 (a), K1 (b).

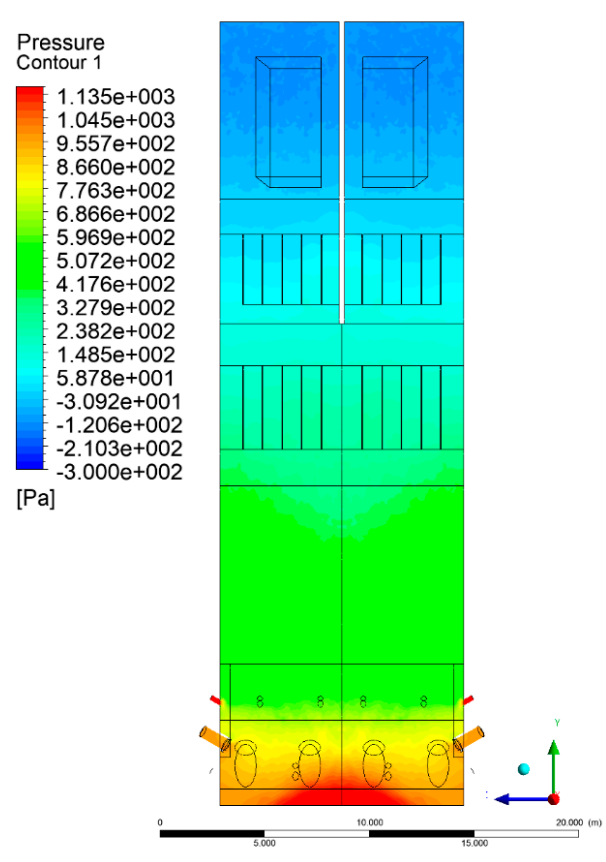

(a)

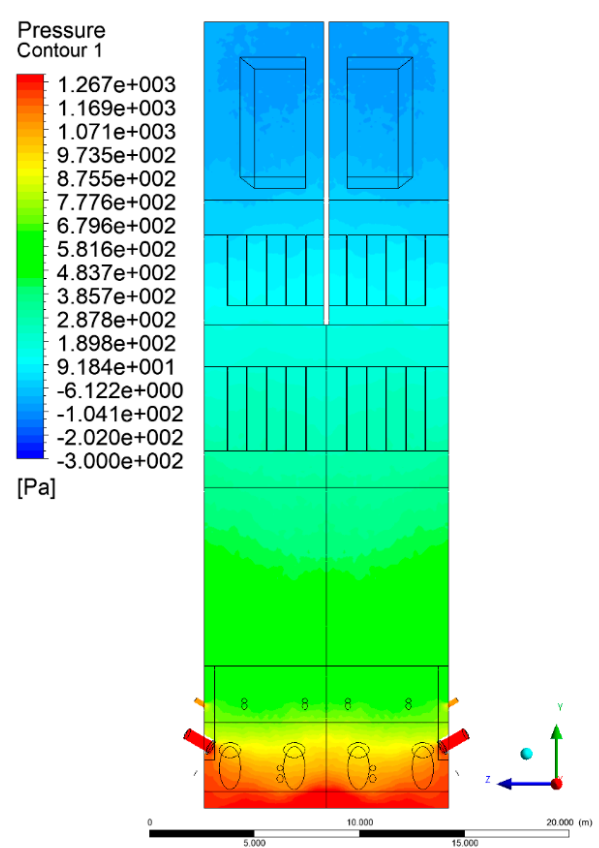

(b)

Figure 5. Pressure distribution, sectional view Y-Z-3, variants K2 (a), K3 (b). 


\subsection{Velocity Distribution in the Combustion Chamber}

Figures 6-9 show the velocity distributions of the reactive gas mixture in the computational domain. In reference case $\mathrm{K} 0$ (Figure $6 \mathrm{a}$ ), the velocity varied in the range 4 to $12 \mathrm{~m} / \mathrm{s}$, excluding the areas near individual air inlets, due to significant disturbances. The sectional views $X-Y$ allow noticing of slight flow turbulence, which results mainly from the spatial configuration of air nozzles.

The velocity increase in each of the examined cases is observed in the platen superheater zones, corresponding to the reduced cross-sectional area. Such conditions favored the erosion process in this part of the furnace [21]. The flow characteristics were mainly the result of air and gas flows and negative pressure in the upper part of the combustion chamber. The gas supply affected, to some extent, the velocity distribution in the calculation domain due to the direct physicochemical relationship of the reactive mixture with its local composition and temperature. The supply of additional syngas to the combustion chamber in Variants K1, K2, and K3, caused the manifestation of additional gas sources in the combustion chamber. Moreover, the addition of dioxide-rich fuel gas led to an increase in temperature inside the furnace and $\mathrm{CO}_{2}$ concentration inside the lower part of the combustion chamber.

Figures 8 and 9 show data on Y-Z cuts indicated upward flow direction, and moderate velocity in the central part of the furnace in each of the examined cases, which is consistent with the real behavior of the system, and allows us to state that the model is fully applicable for case studies of heat transfer by convection and radiation within said domain. The modification of boundary conditions (including the composition of the mixture at the domain inlets) allows obtaining clear and unambiguous information on the influence of such changes on the thermodynamic state of the system. Therefore, it is possible to exclude the influence of instability (caused by the change of boundary conditions) in solving the continuity and momentum conservation equations.

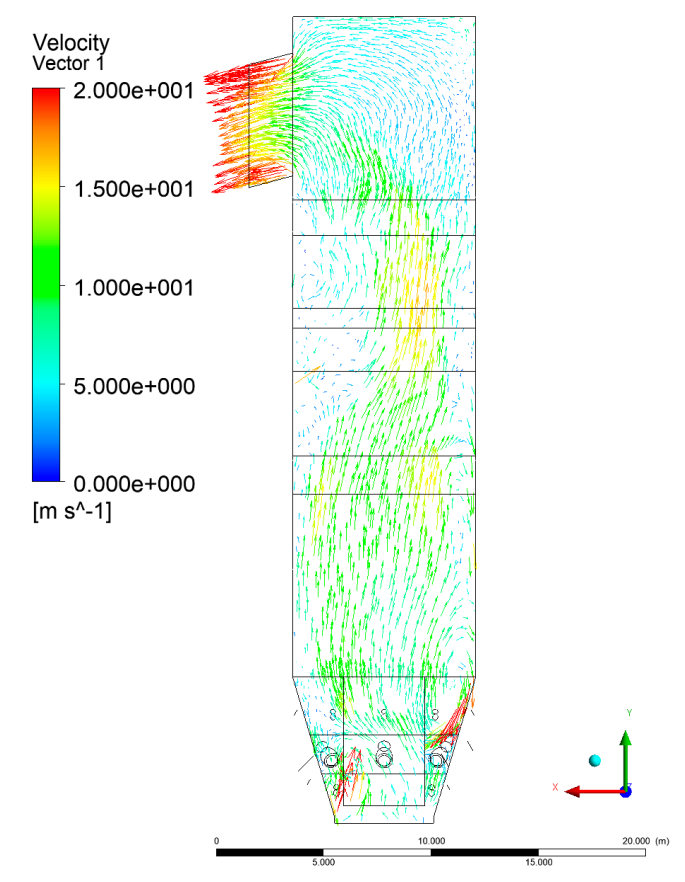

(a)

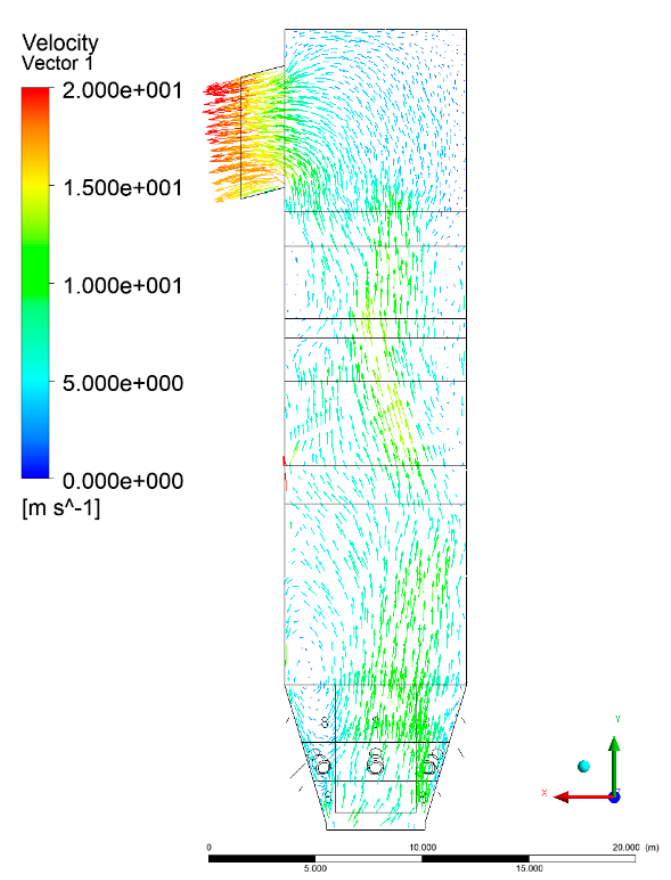

(b)

Figure 6. Gas velocity profiles, sectional view X-Y-3, (a) Variant K0, (b) Variant K1. 


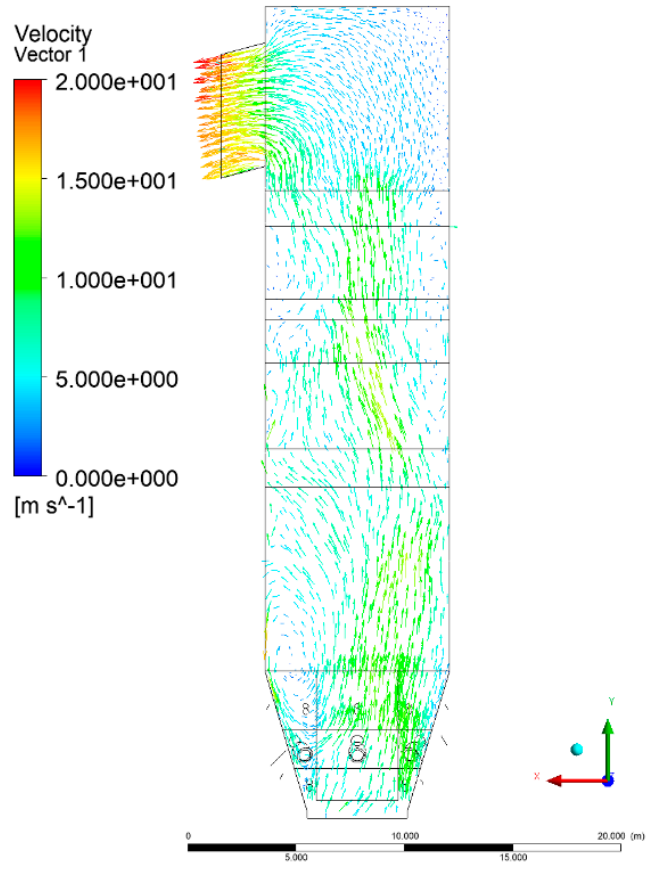

(a)

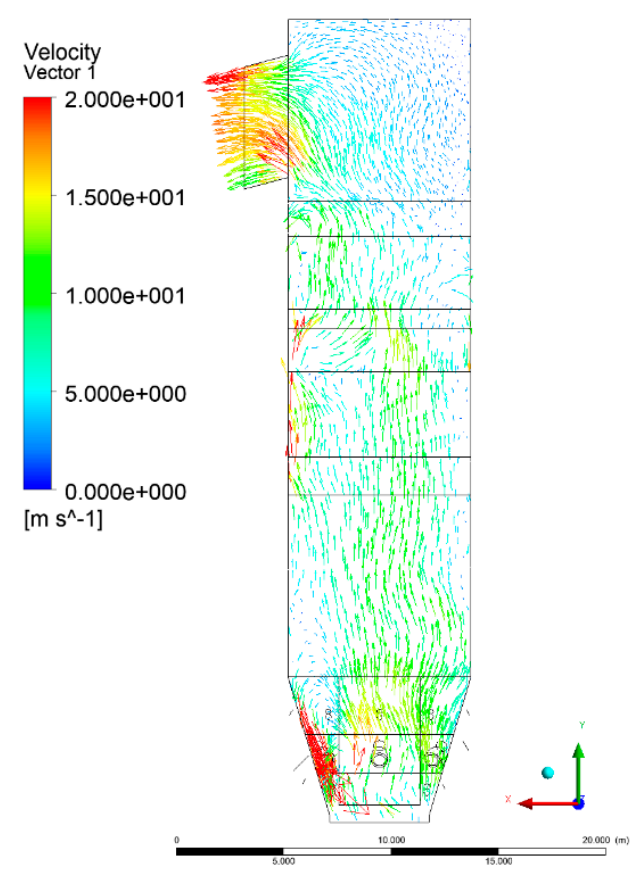

(b)

Figure 7. Gas velocity profiles, sectional view X-Y-3, (a) Variant K2, (b) Variant K3.

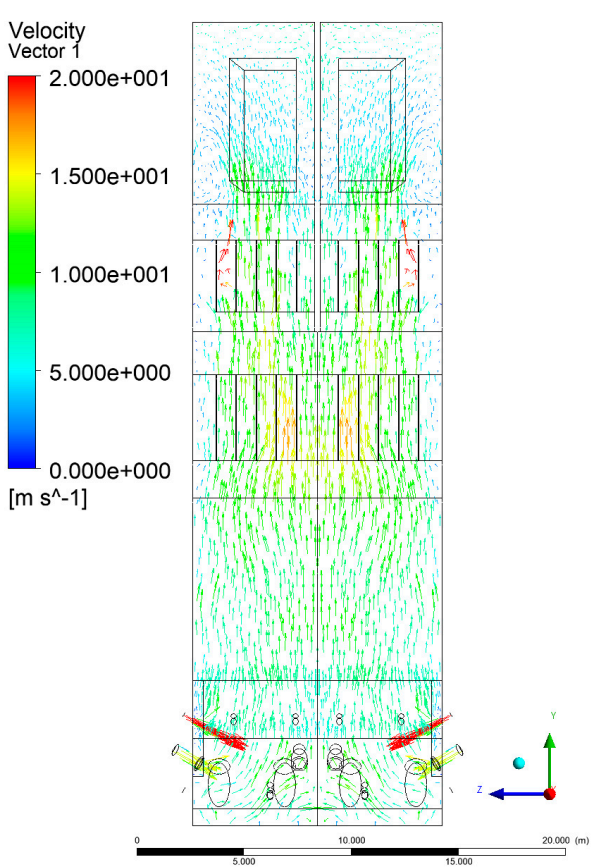

(a)

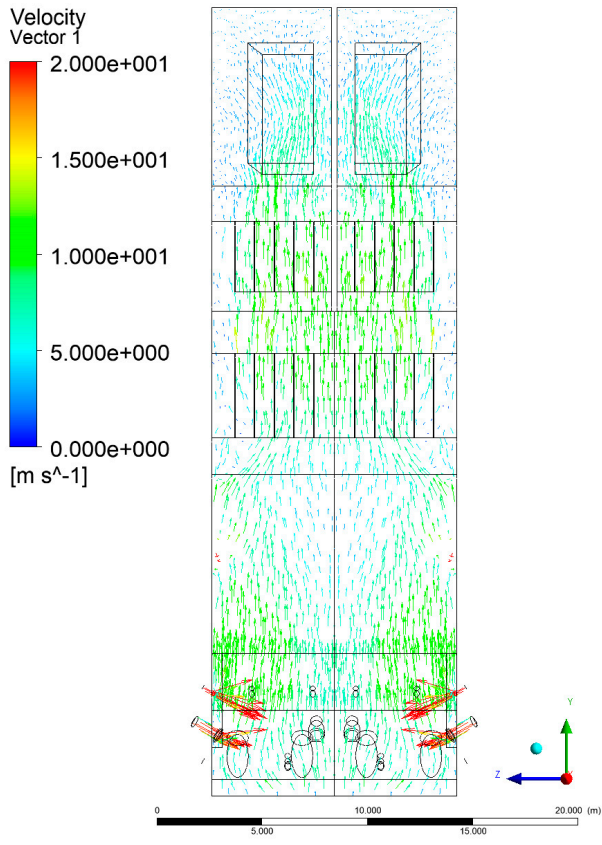

(b)

Figure 8. Gas velocity profiles, sectional view Y-Z-3, (a) Variant K0, (b) Variant K1. 


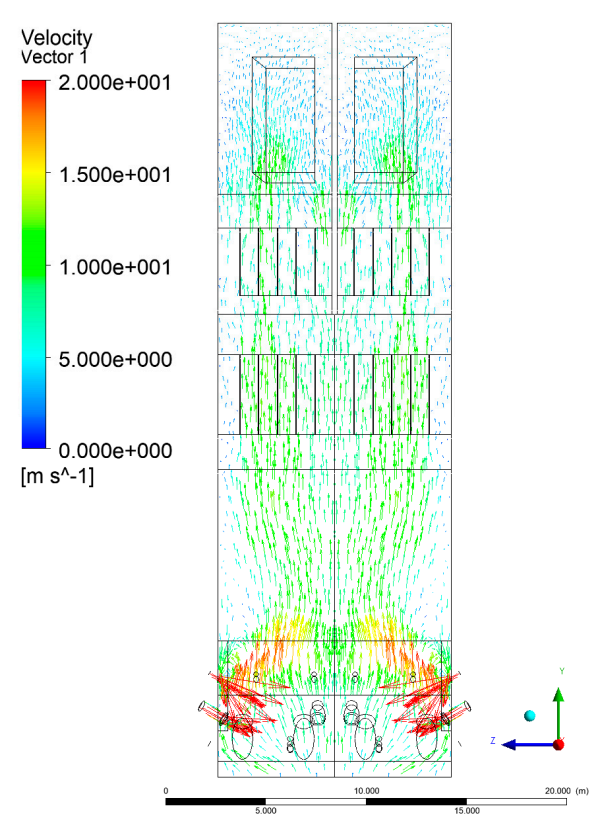

(a)

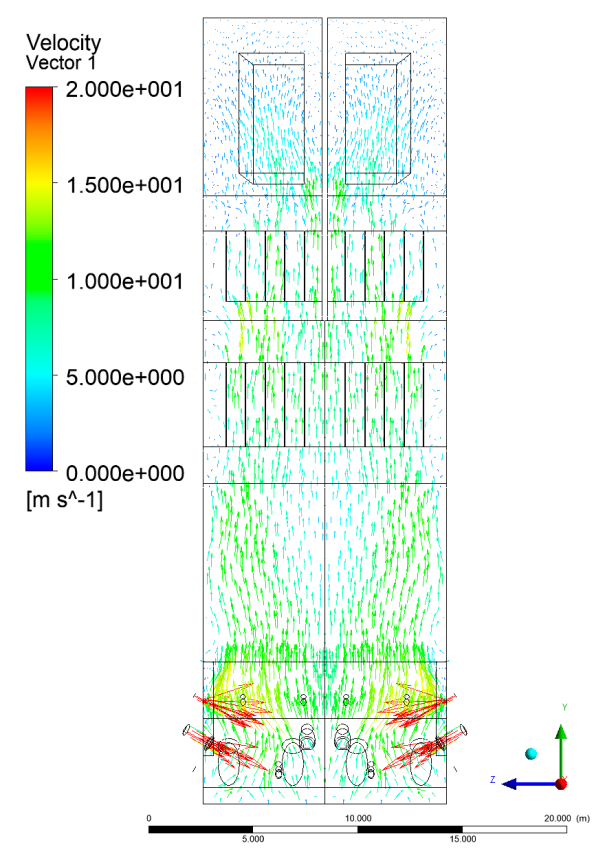

(b)

Figure 9. Gas velocity profiles, sectional view Y-Z-3, (a) Variant K2, (b) Variant K3.

\subsection{Combustion Chamber Temperature Distribution}

In the reference case $\mathrm{K} 0$, a slight anisotropy of temperature distribution was visible in the $\mathrm{X}-\mathrm{Y}$ and $\mathrm{Y}-\mathrm{Z}$ sectional views. Conditions were much more homogeneous along the $\mathrm{X}$-axis of the system, while local temperature changes resulted from the stationary model application. In the considered sectional views, temperature of a fluidized bed varied in the range of $750-850{ }^{\circ} \mathrm{C}$. Due to the nature of the boundary conditions of the primary air inlet (homogeneous mass flux), a narrow area of local, relatively low temperatures, close to the air feed point, could be reported. Thus, the calculated temperature profile, in comparison to the experimental one, was shifted down towards the grid. However, the local temperatures, consistent with the experimental data equal to $\sim 850{ }^{\circ} \mathrm{C}$, were also registered.

The X-Y cuts indicated a shift of the area with the highest combustion intensity slightly towards the rear wall of the boiler, which was undoubtedly related to the location of the fuel feeders in this zone. An increase in temperature above the fuel feeding zone was observed. The central feeders supply fuel, and due to the impact of air inflow (Variant K0) on the front wall of the boiler, it slightly deviated from the original flight path towards the sidewalls, which was also visible in gas velocity profiles. This interaction was essential when considering the syngas supplied by this burner, as the spatial air concentration changed. The results obtained for cut Y-Z-3 indicated that in Variant K0, the air supplied by two start-up burners closest to the coal feeders (sidewall) had a positive effect on combustion efficiency, which was expressed in higher-temperature fields in the mixing zone of fuel and air. Therefore, these airstreams were not considered for replacement with syngas in further calculations.

A slight decrease in temperature in the wall regions was demonstrated in each sectional view as an effect of bed-to-wall heat transfer, mainly due to high suspension density on the membrane-walls [22]. However, the higher solids concentration on the walls (inert material, fuel, ash after fuel burnout) resulted in slight convergence problems in the CFD model [23,24]. Despite the high density of the grid, its cells were still large, which means that there was a relatively significant distance between the wall and the first node closest to the wall, where it was necessary to interpolate the temperature profile $[25,26]$. In some cases, it manifested a local increase in temperature next to the walls (visible also in the section of platen superheaters). For a smaller scale of the system, a solution might be the use of a higher-density grid in the wall layer, which, nevertheless, always results in a significant increase in the total number of control cells and drastically extends the computational time [27]. These problems 
do not exist in zones of greater distance from the walls, so the discussed effect did not influence the obtained results.

Due to the local character of changes resulting from the modification in air and fuel supply, the temperature distributions in Variants K1-K3 were best demonstrated by the sections containing the start-up burners or adjacent areas, especially Y-Z-2 and Y-Z-3, as well as X-Y-4 or X-Y-5 sectional views.

The results demonstrate a significant influence of the syngas supply by the start-up burners on local temperature increase in the domain (Figures 10-30). The effect is observed as reaction zones of flammable gas components at short distances from the inlet to the combustion chamber (e.g., sectional views Y-Z: Figure 13, and X-Y: Figures 23-30).

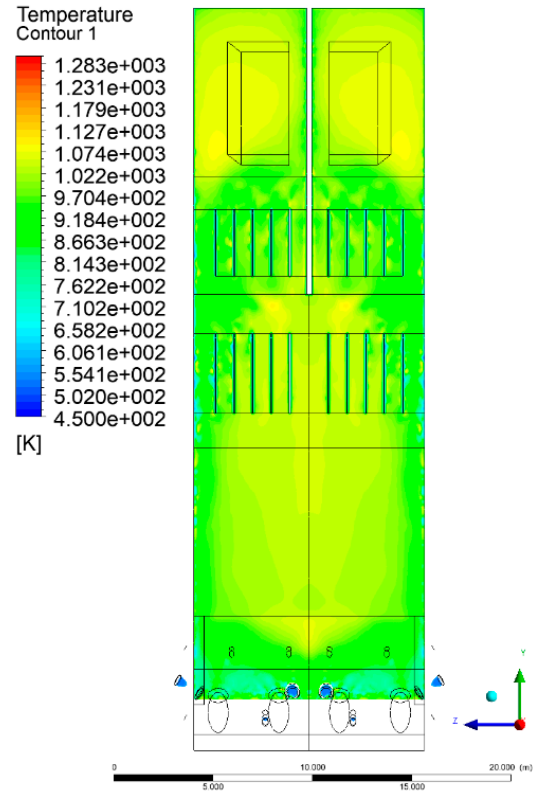

(a)

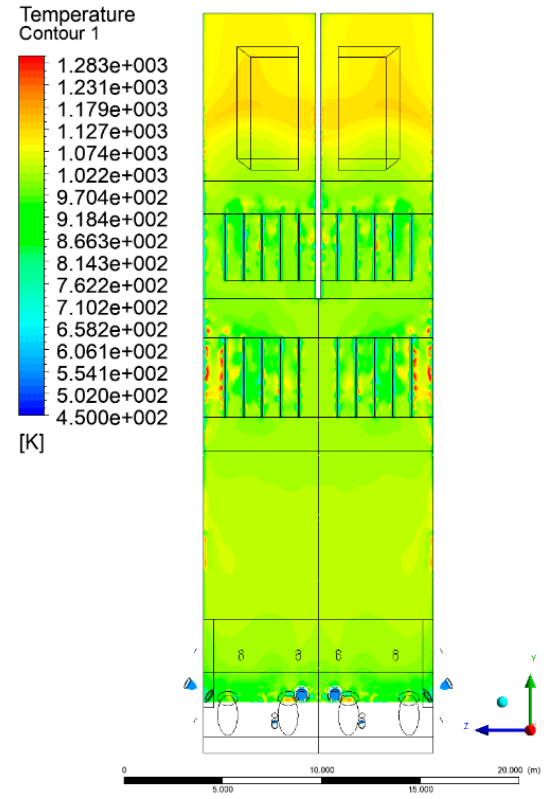

(b)

Figure 10. Temperature distribution, sectional view Y-Z-1, (a) Variant K0, (b) Variant K1.

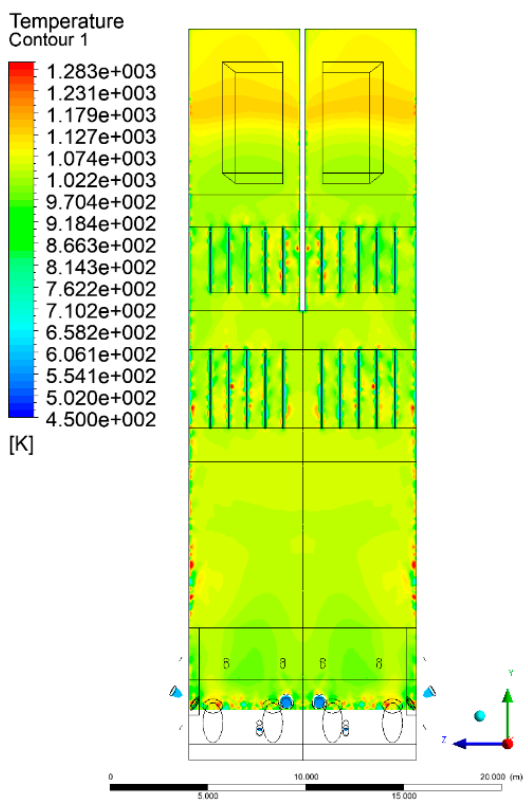

(a)

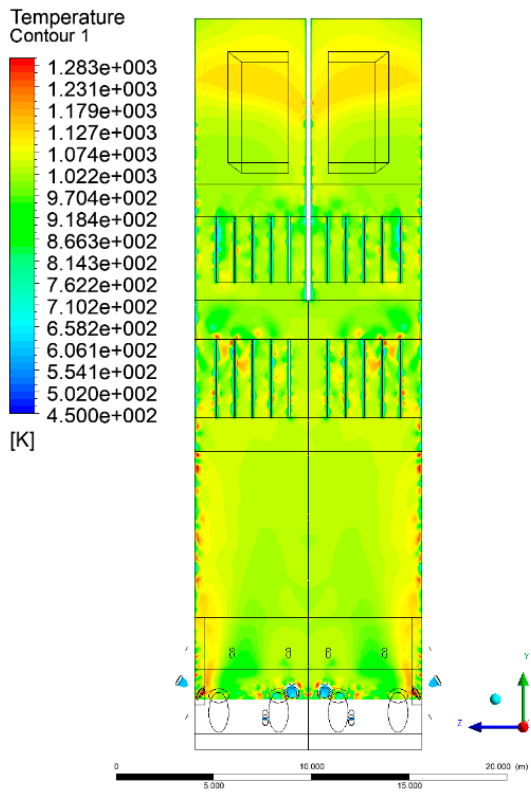

(b)

Figure 11. Temperature distribution, sectional view Y-Z-1, (a) Variant K2, (b) Variant K3. 


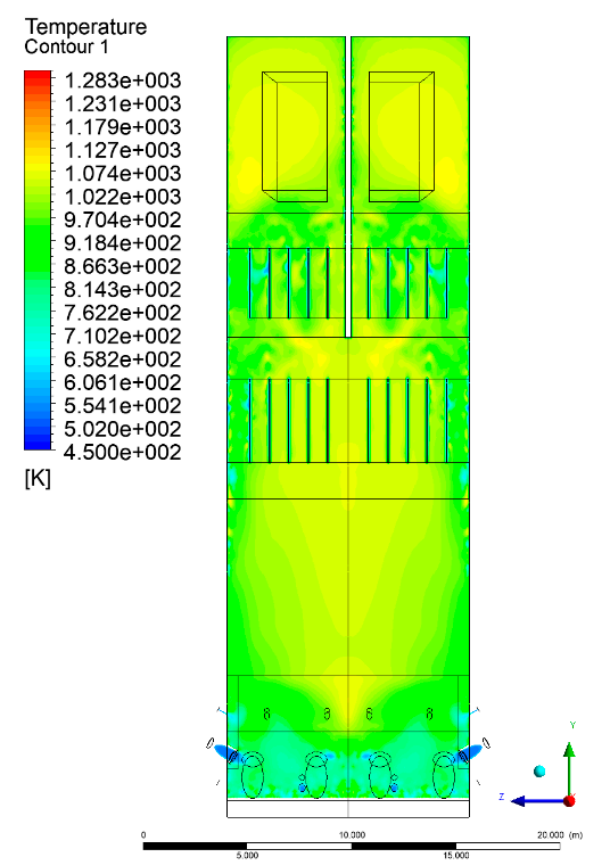

(a)

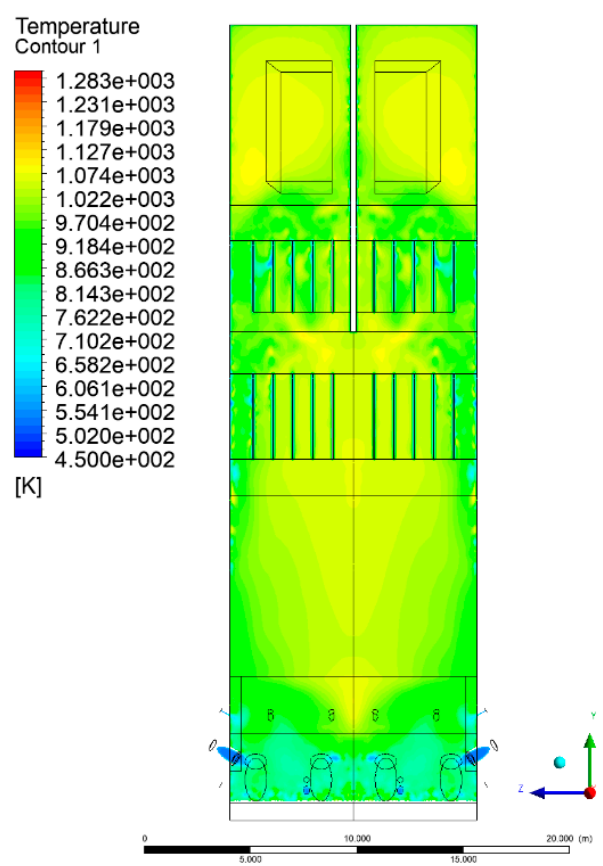

(b)

Figure 12. Temperature distribution, sectional view Y-Z-2, (a) Variant K0, (b) Variant K1.

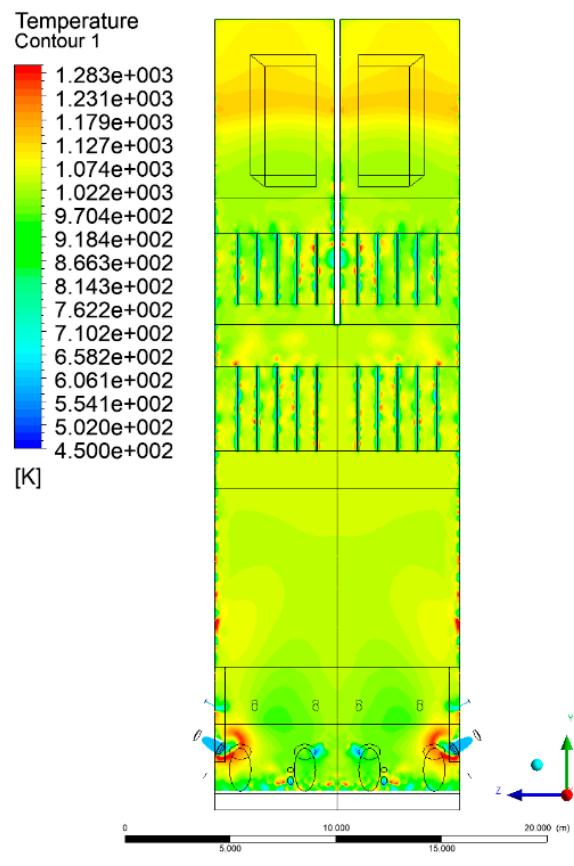

(a)

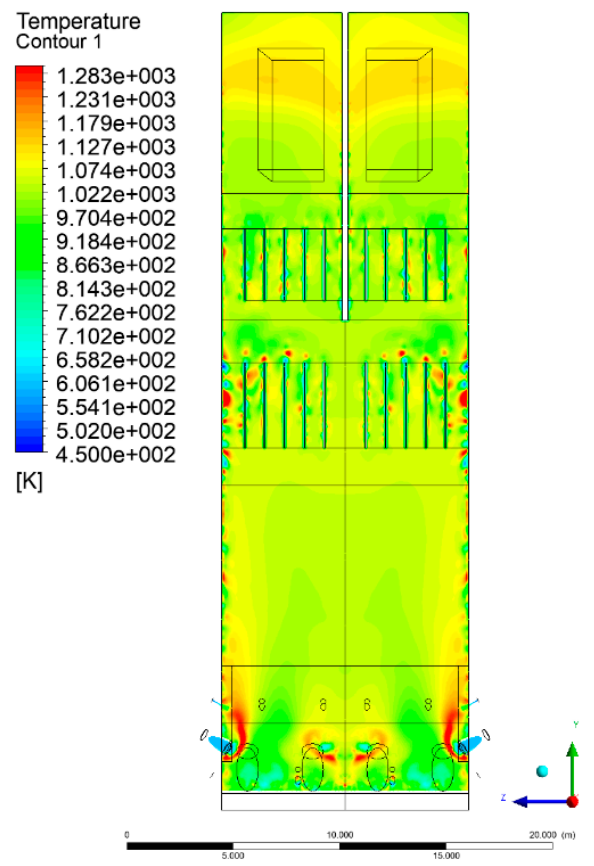

(b)

Figure 13. Temperature distribution, sectional view Y-Z-2, (a) Variant K2, (b) Variant K3. 


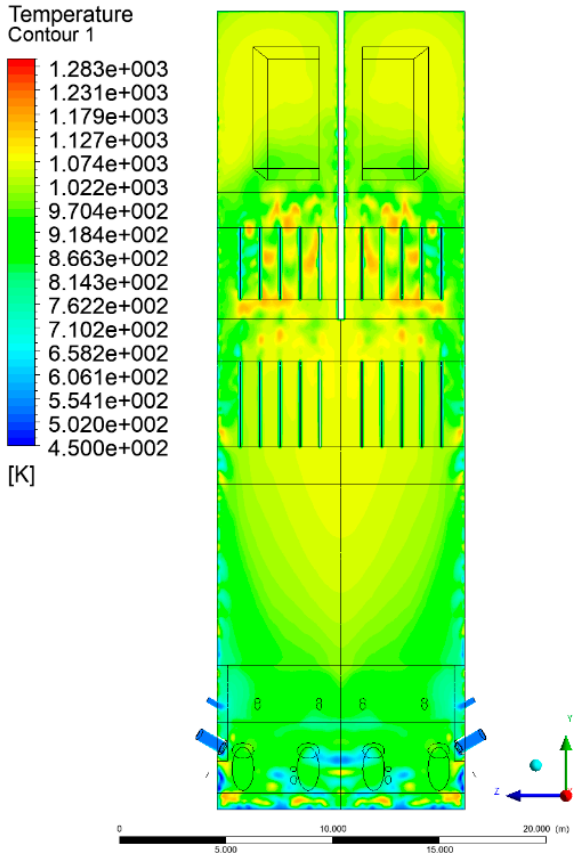

(a)

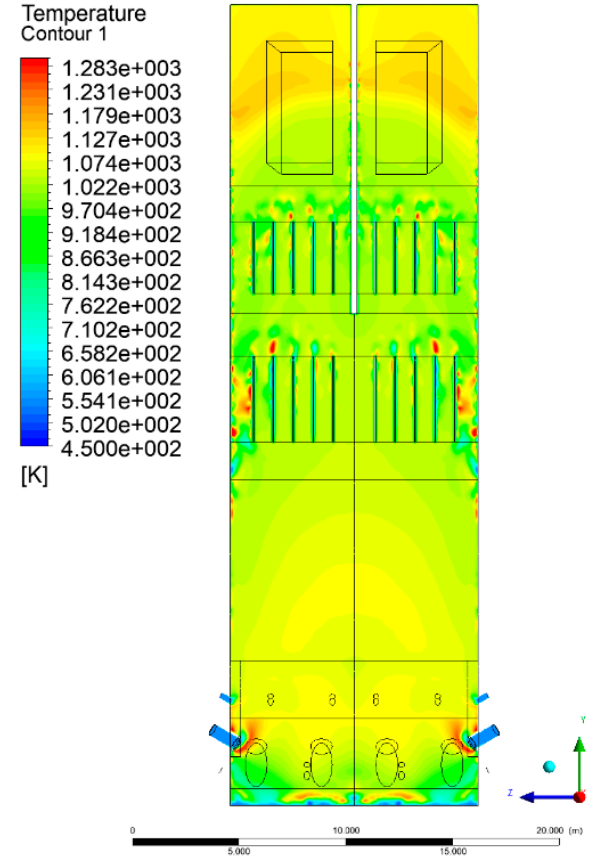

(b)

Figure 14. Temperature distribution, sectional view Y-Z-3, (a) Variant K0, (b) Variant K1.

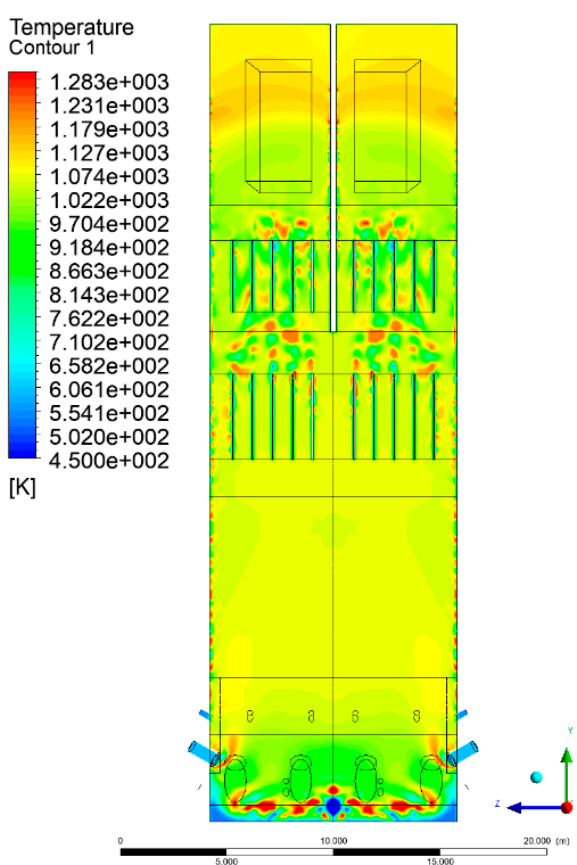

(a)

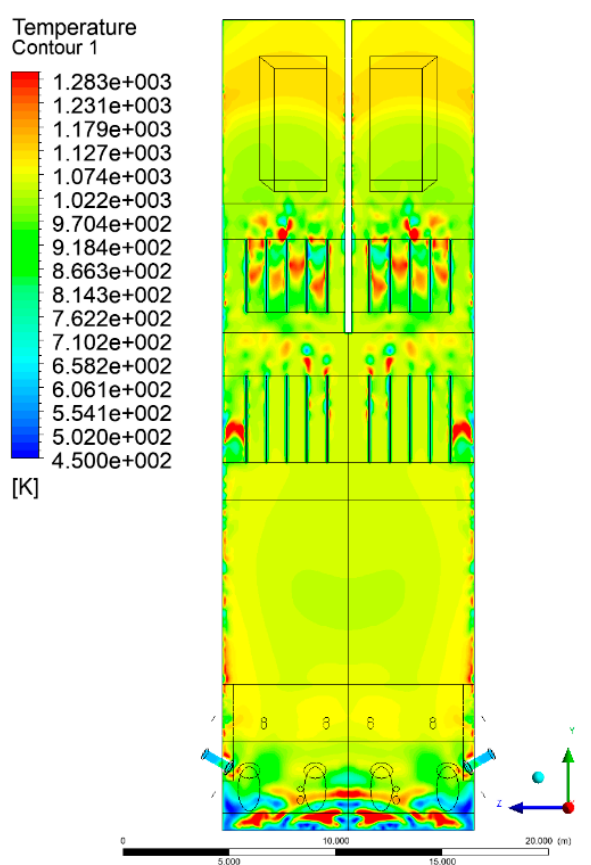

(b)

Figure 15. Temperature distribution, sectional view Y-Z-3, (a) Variant K2, (b) Variant K3. 


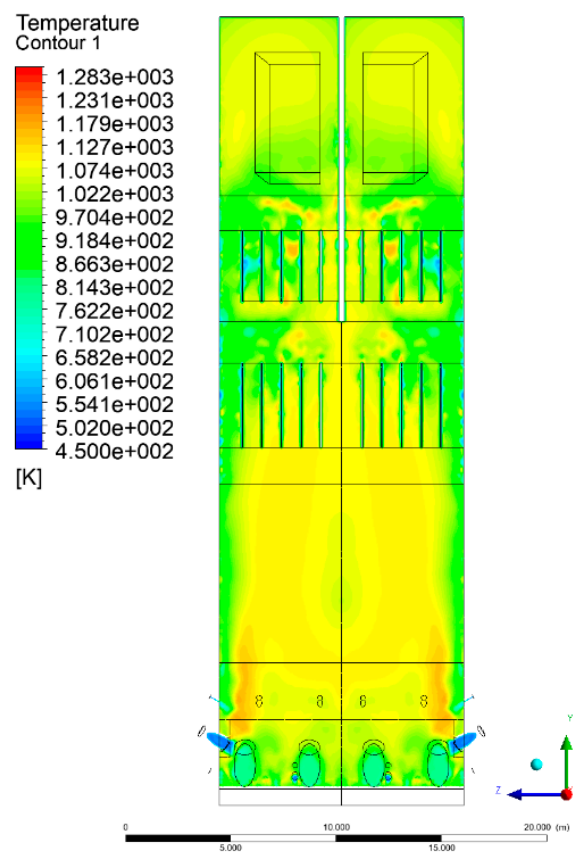

(a)

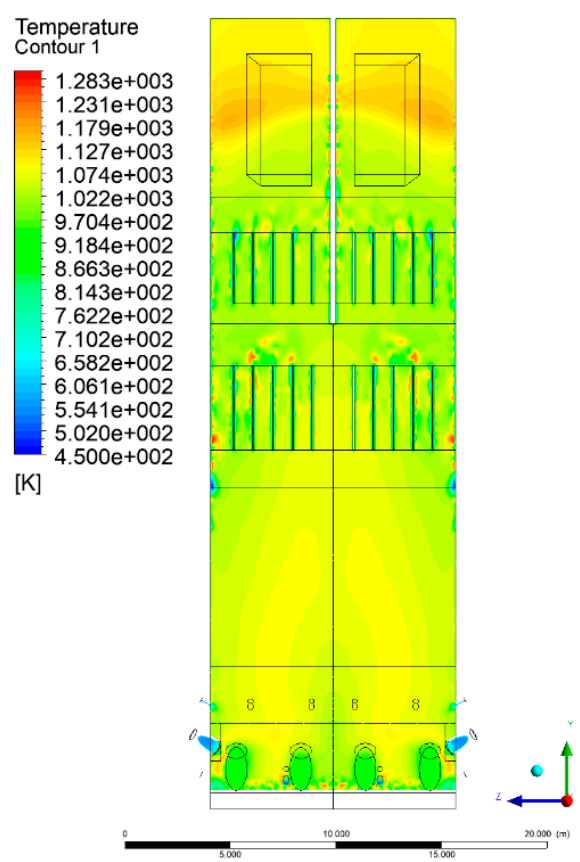

(b)

Figure 16. Temperature distribution, sectional view Y-Z-4, (a) Variant K0, (b) Variant K1.

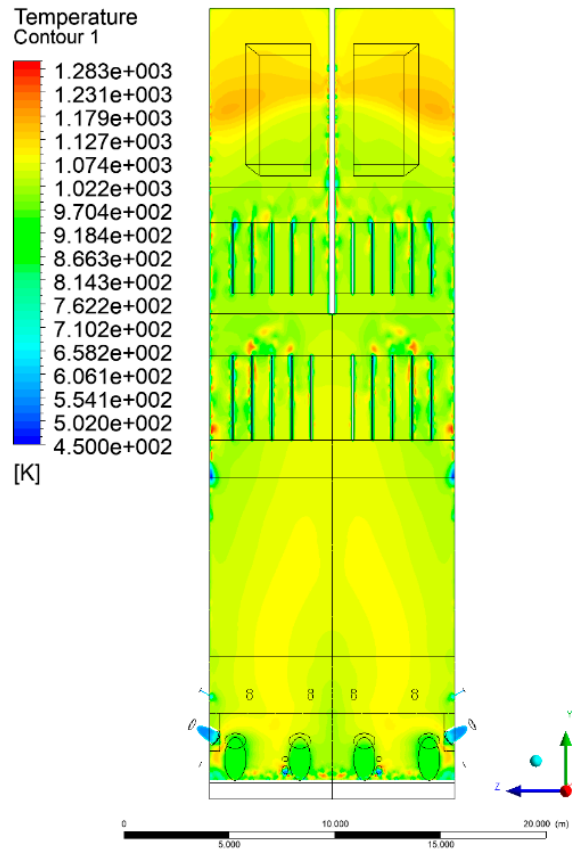

(a)

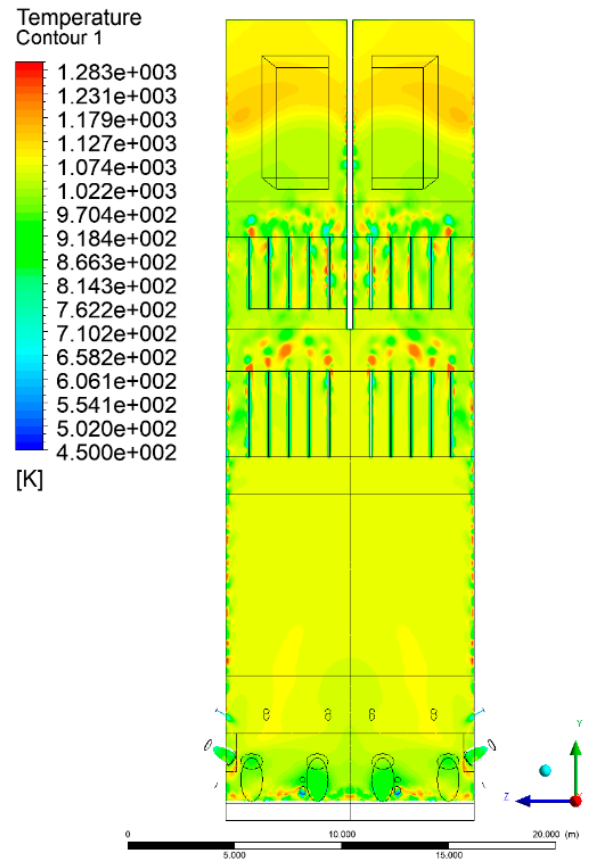

(b)

Figure 17. Temperature distribution, sectional view Y-Z-4, (a) Variant K1, (b) Variant K2. 


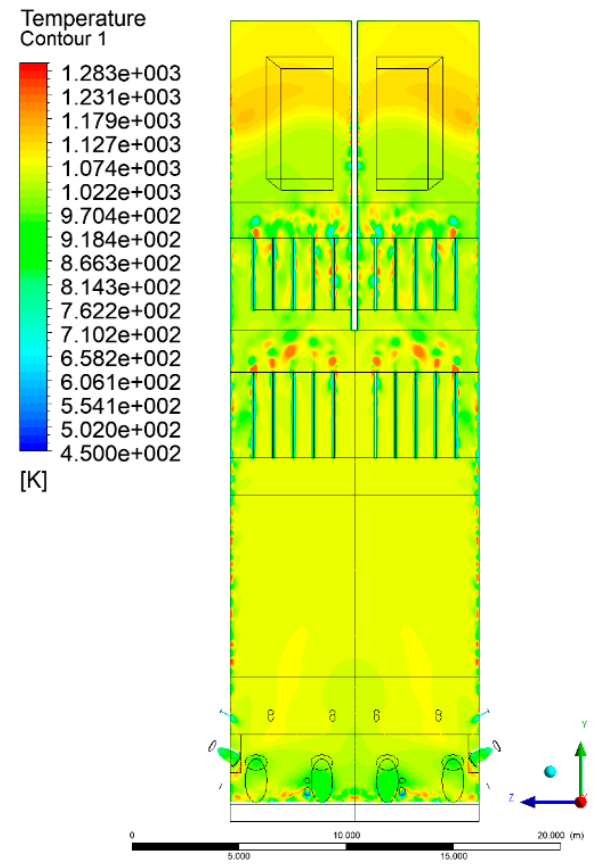

(a)

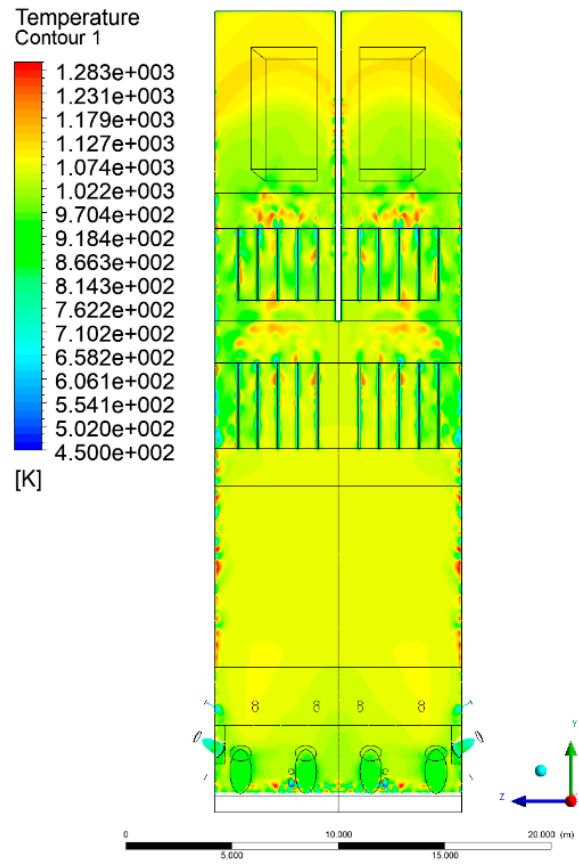

(b)

Figure 18. Temperature distribution, sectional view Y-Z-4, (a) Variant K2, (b) Variant K3.

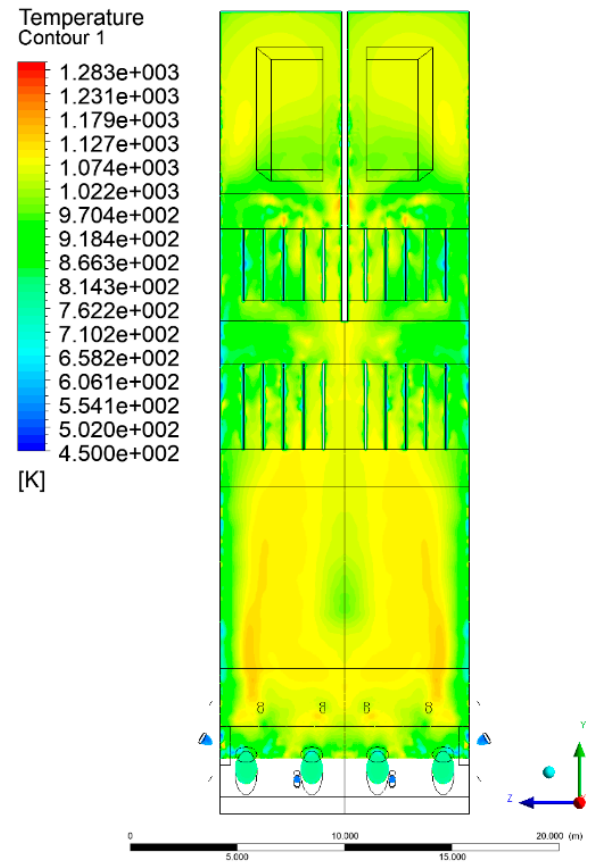

(a)

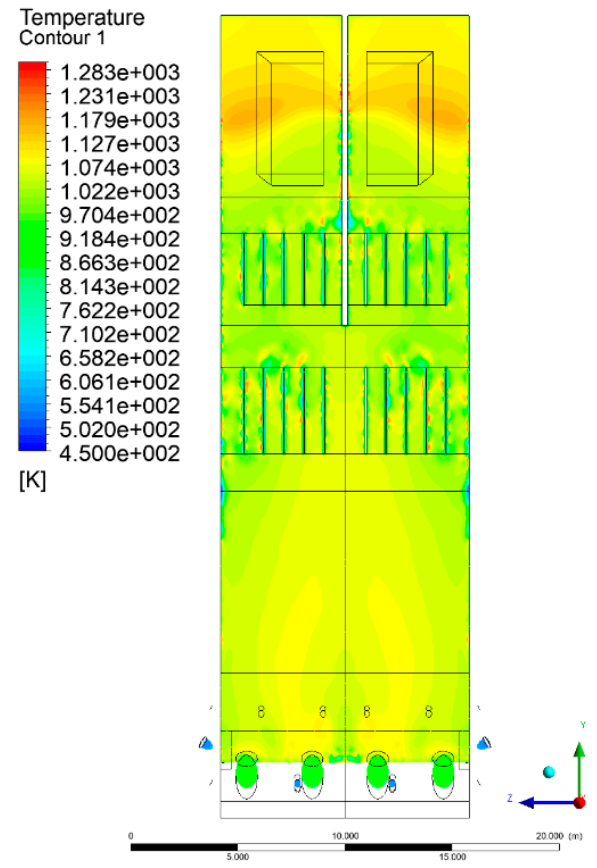

(b)

Figure 19. Temperature distribution, sectional view Y-Z-5, (a) Variant K0, (b) Variant K1. 


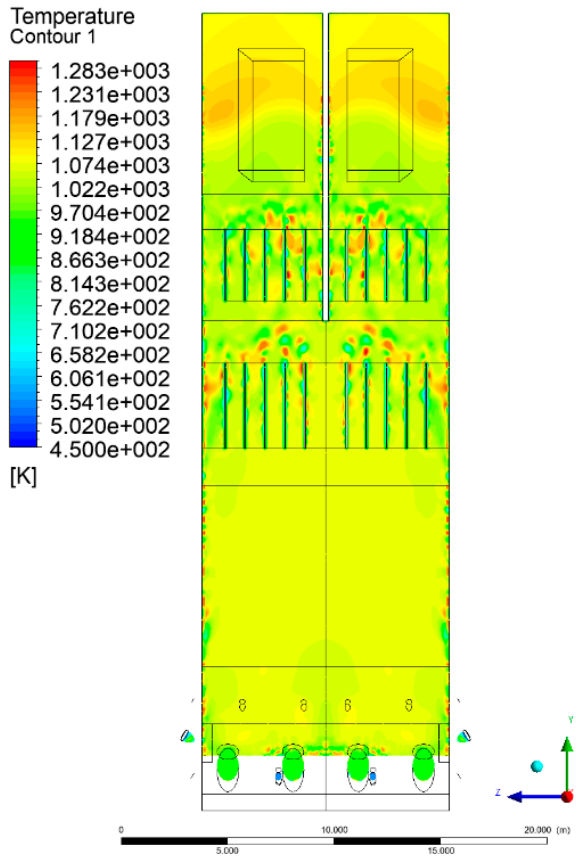

(a)

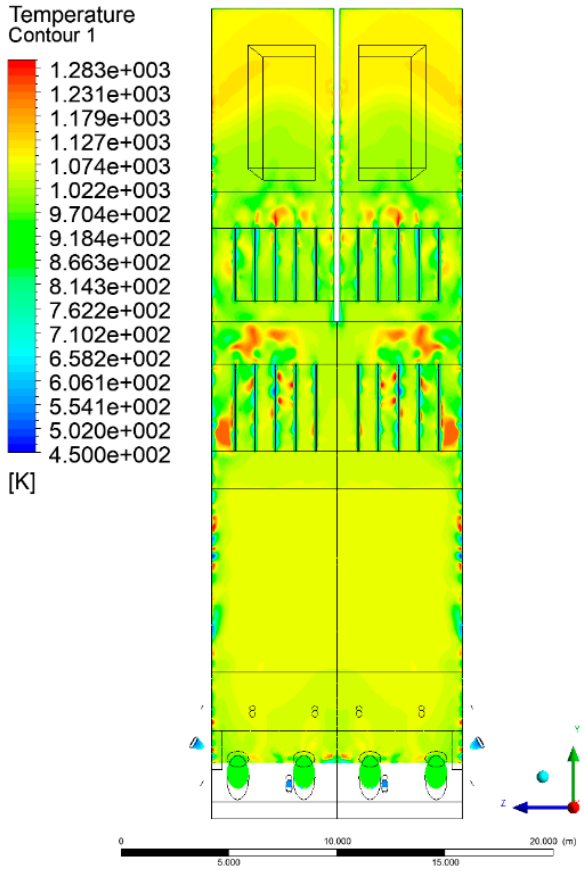

(b)

Figure 20. Temperature distribution, sectional view Y-Z-5, (a) Variant K2, (b) Variant K3.

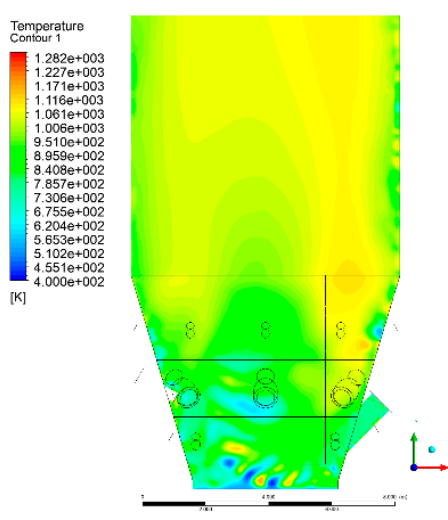

(a)

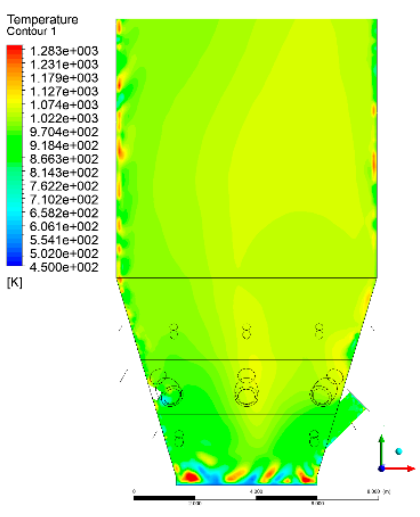

(b)

Figure 21. Temperature distribution, sectional view X-Y-1, Variants (a) K0 and (b) K1.
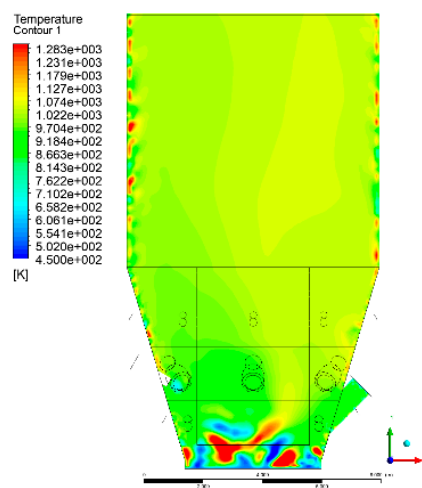

(a)

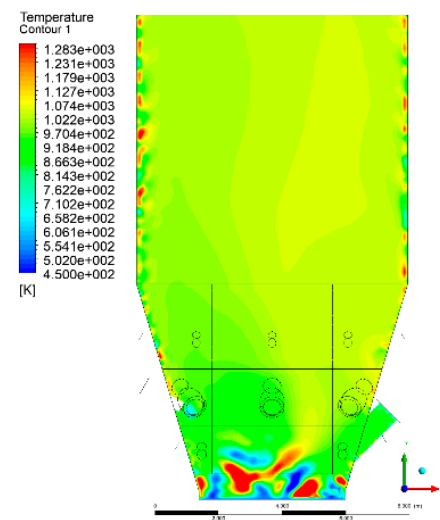

(b)

Figure 22. Temperature distribution, sectional view X-Y-1, Variants (a) K2 and (b) K3. 

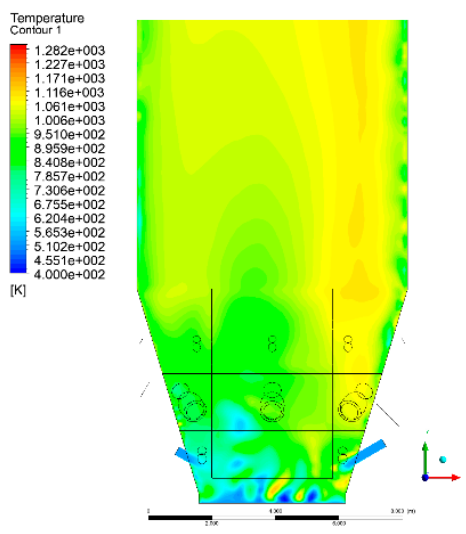

(a)

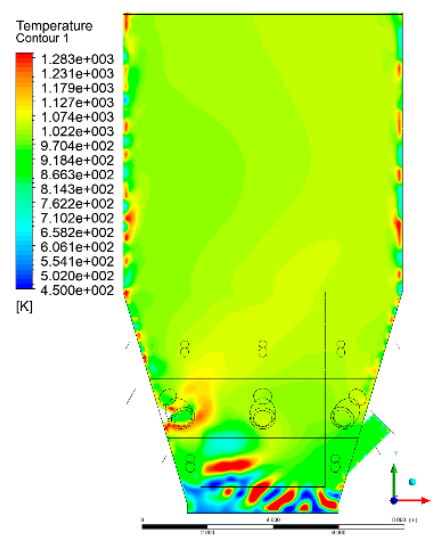

(b)

Figure 23. Temperature distribution, sectional view X-Y-2, Variants (a) K0 and (b) K1.

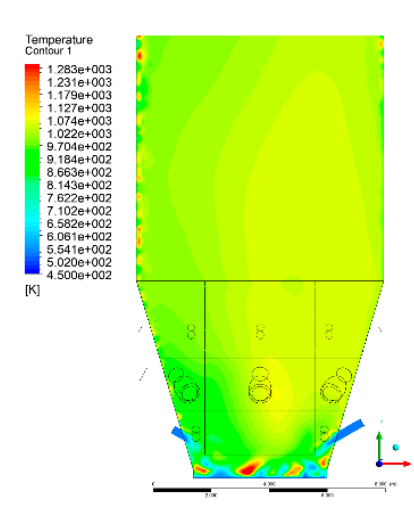

(a)

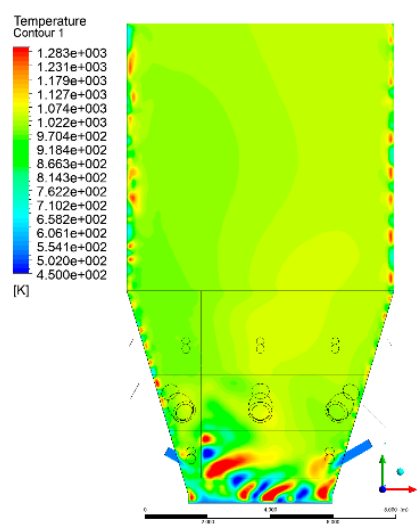

(b)

Figure 24. Temperature distribution, sectional view X-Y-2, Variants (a) K2 and (b) K3.

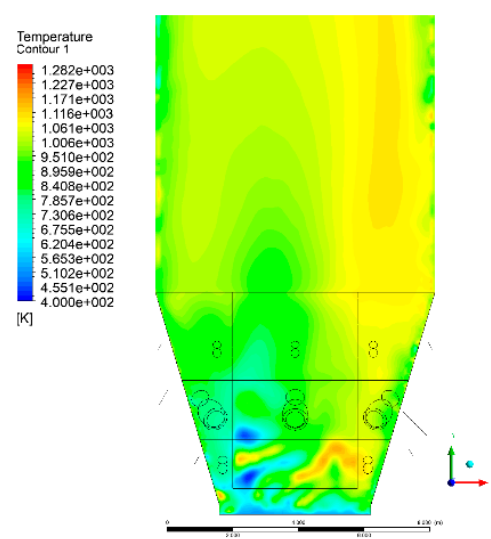

(a)

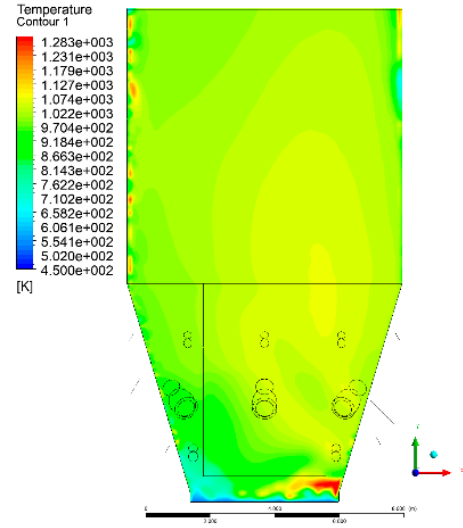

(b)

Figure 25. Temperature distribution, sectional view X-Y-3, Variants (a) K0 and (b) K1. 


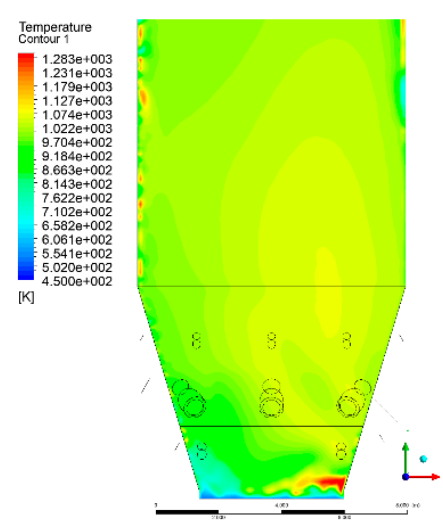

(a)

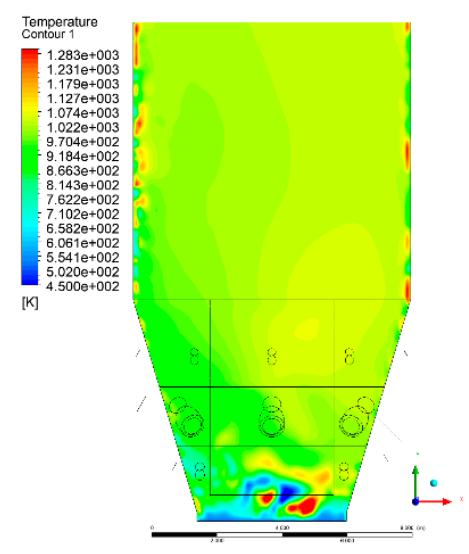

(b)

Figure 26. Temperature distribution, sectional view X-Y-3, Variants (a) K2 and (b) K3.
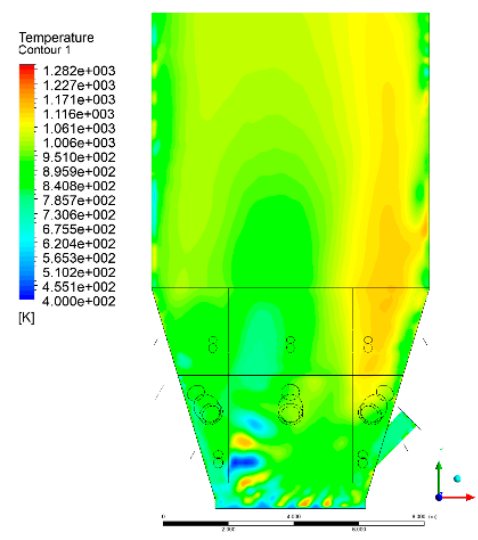

(a)

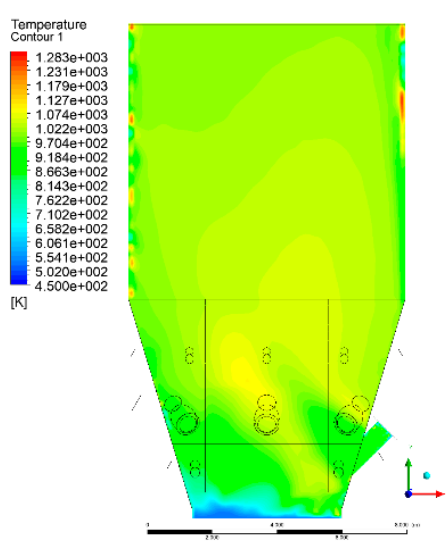

(b)

Figure 27. Temperature distribution, sectional view X-Y-4, Variants (a) K0 and (b) K1.

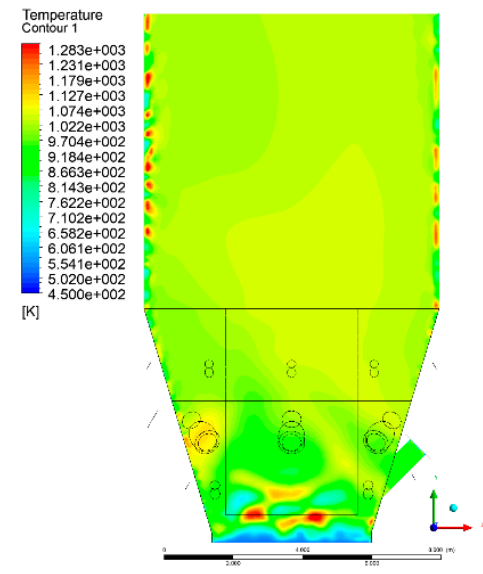

(a)

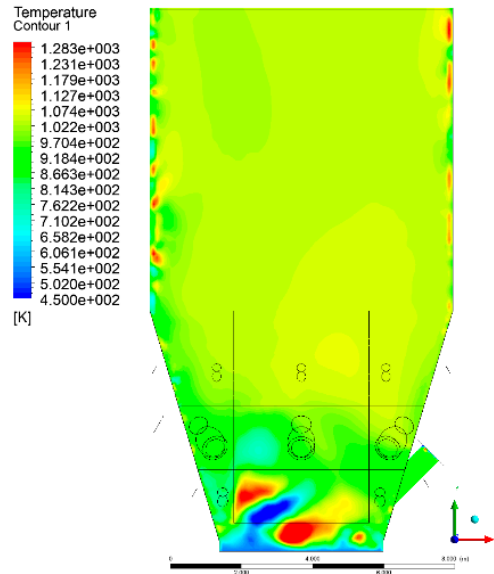

(b)

Figure 28. Temperature distribution, sectional view X-Y-4, Variants (a) K2 and (b) K3. 


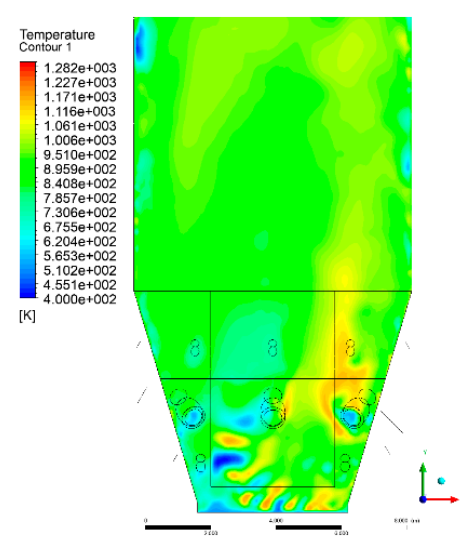

(a)

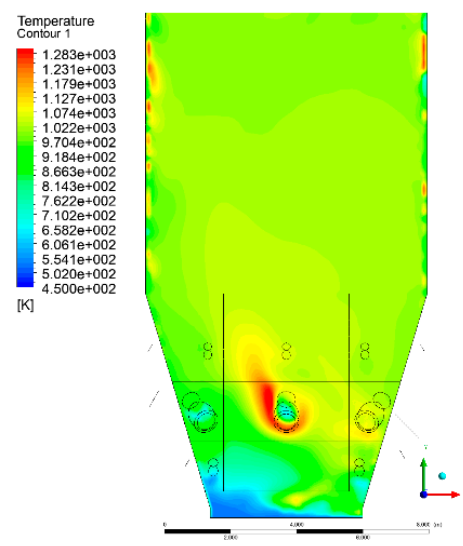

(b)

Figure 29. Temperature distribution, sectional view X-Y-5, Variants (a) K0 and (b) K1.

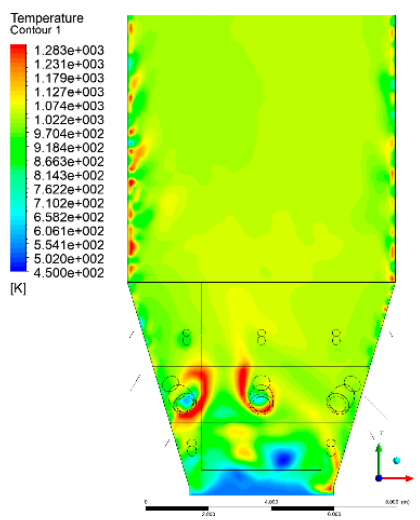

(a)

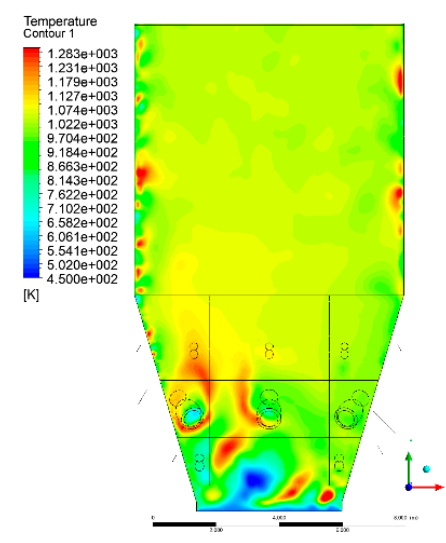

(b)

Figure 30. Temperature distribution, sectional view X-Y-5, Variants (a) K2 and (b) K3.

The unreacted or partially reacted $(\mathrm{CH} 4 \rightarrow \mathrm{CO})$ syngas moved to the lower parts of the combustion chamber, where it reacted with primary air. It caused a local temperature increase and shifted down the combustion zone of solid fuel due to its temperature rise. The effect was visible in the form of a local temperature rise reaching and even locally exceeding $1000^{\circ} \mathrm{C}$. Such a situation may lead to de-fluidization due to the melting or fusion of bed solids [16].

Moreover, a significant reduction in oxidant access to solid fuel was demonstrated, despite the reduction in coal and being supplanted by syngas. Differences in the combustion kinetics in the gaseous (homogeneous) phase, and coal combustion (heterogeneous phase) resulted in the favoring of combustible gas in the global chemistry of the processes taking place in the combustion zone. This may be explained by the fact that the combustion of char is a two-step process comprising of oxygen transportation to the carbon surface and the reaction of carbon with oxygen on said carbon surface [28-31]. This effect is visible even in the case of such a simple combustion mechanism as that used in the developed CFD model.

It is also worth emphasizing that due to the relatively low complexity of the model, the analysis did not cover many additional aspects related to the condition changes in the combustion chamber. The issues of $\mathrm{NO}_{\mathrm{x}}$ emissions directly related to the temperature distribution in the combustion chamber was also essential in the considered cases [32-36].

Therefore, it should be concluded that the discussed idea is not recommended for use in the considered CFB unit. The obtained results confirm the statement underlined in [6,37], that the fuel range of an individual boiler depends on various factors, including fuel properties and furnace design parameters. 


\subsection{Combustion Chamber Carbon Dioxide Concentrations}

Because the syngas supplied in the $\mathrm{K} 1-\mathrm{K} 3$ variants is rich in carbon dioxide, the concentration of this compound in the calculation domain increased in individual cases, not only due to the formation of additional combustion zones, but also through the distribution of $\mathrm{CO}_{2}$ from the gas flowing into the furnace. The effect was visible in the presented sectional views (Figures 31-50). Due to different properties (specific heat, density, thermal conductivity) of the reactive mixture and the gas supplied, changes in local $\mathrm{CO}_{2}$ concentrations were observed, generating local zones rich in this compound.

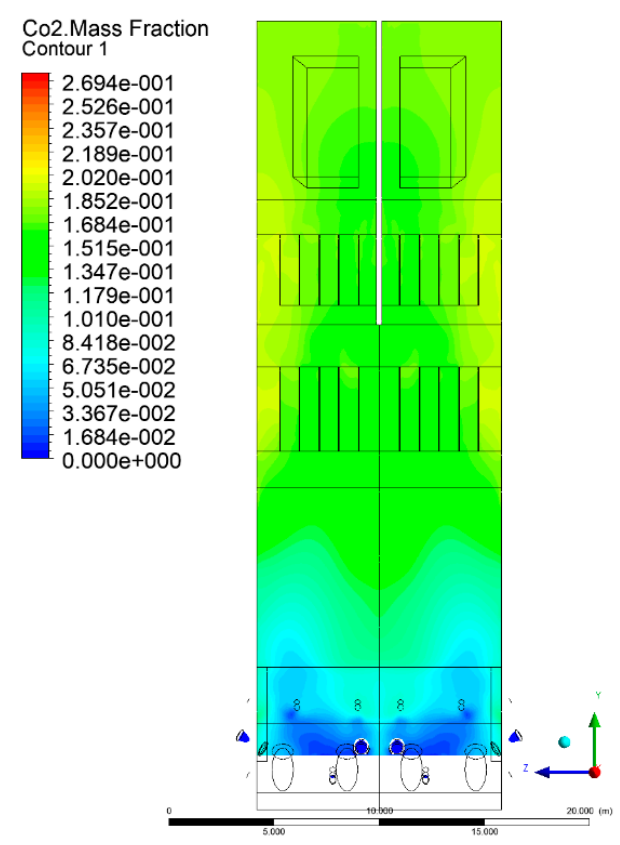

(a)

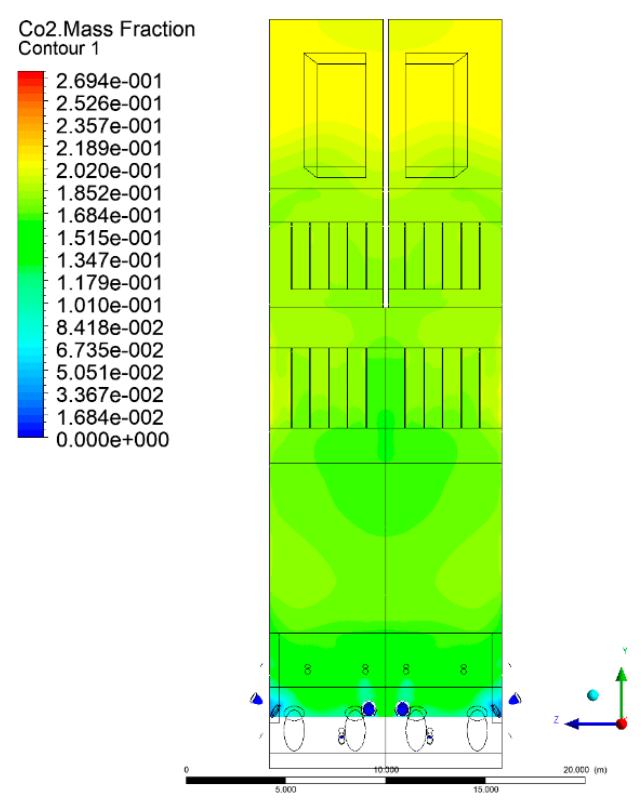

(b)

Figure 31. $\mathrm{CO}_{2}$ concentration in the chamber for sectional view Y-Z-1, (a) Variant K0, (b) Variant K1.

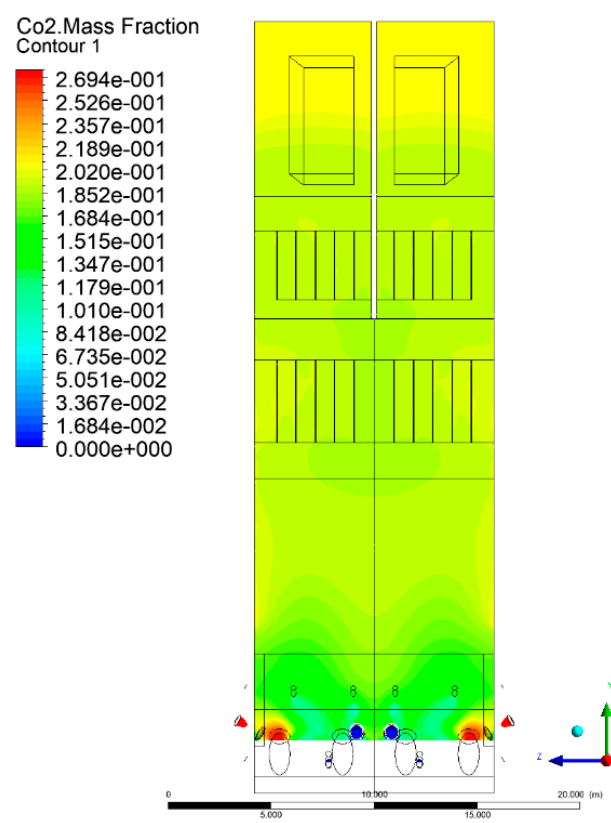

(a)

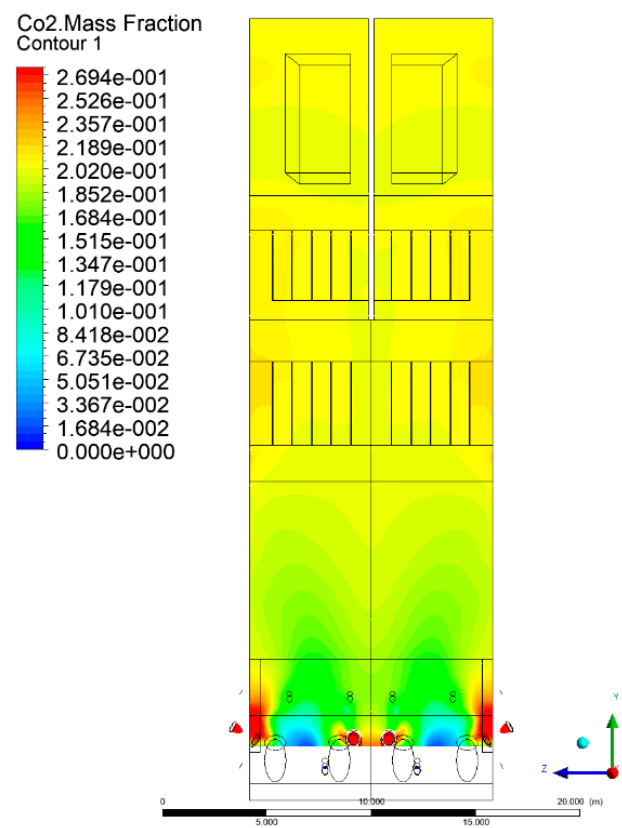

(b)

Figure 32. $\mathrm{CO}_{2}$ concentration in the chamber for sectional view Y-Z-1, (a) Variant K2, (b) Variant K3. 


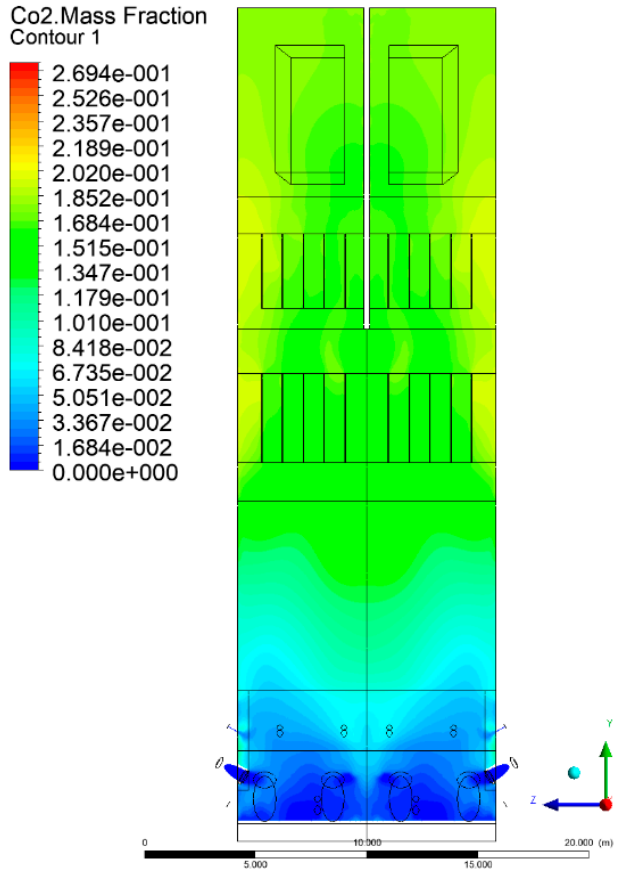

(a)

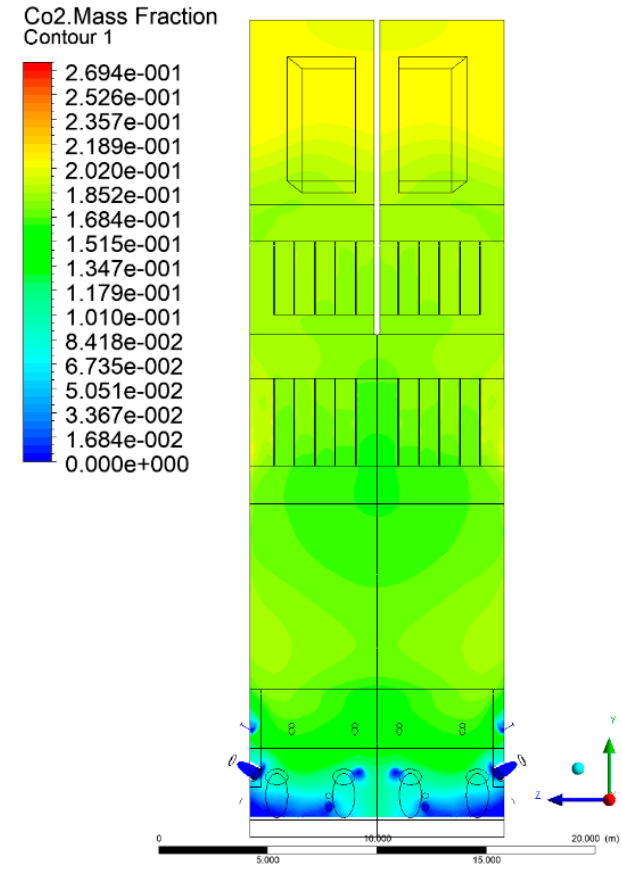

(b)

Figure 33. $\mathrm{CO}_{2}$ concentration in the chamber for sectional view Y-Z-2, (a) Variant K0, (b) Variant K1.

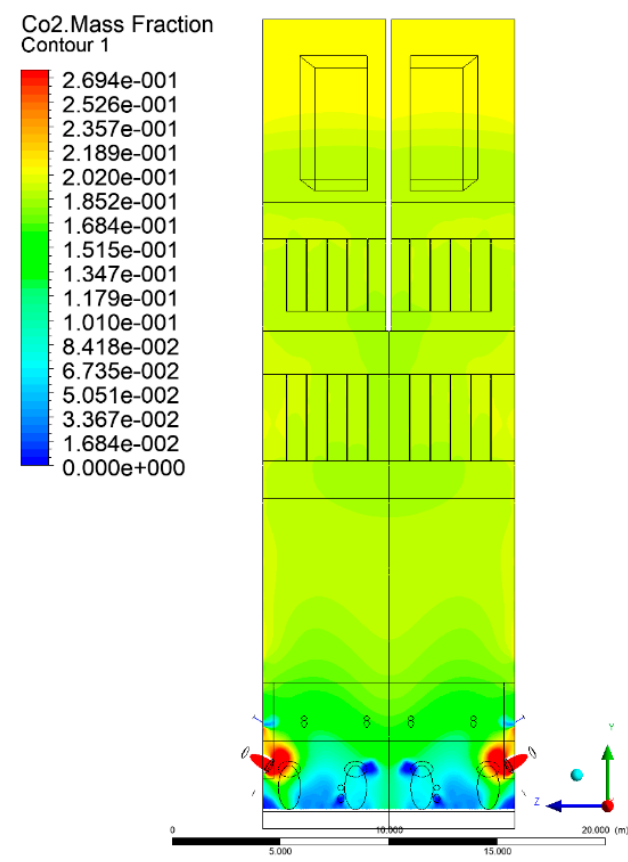

(a)

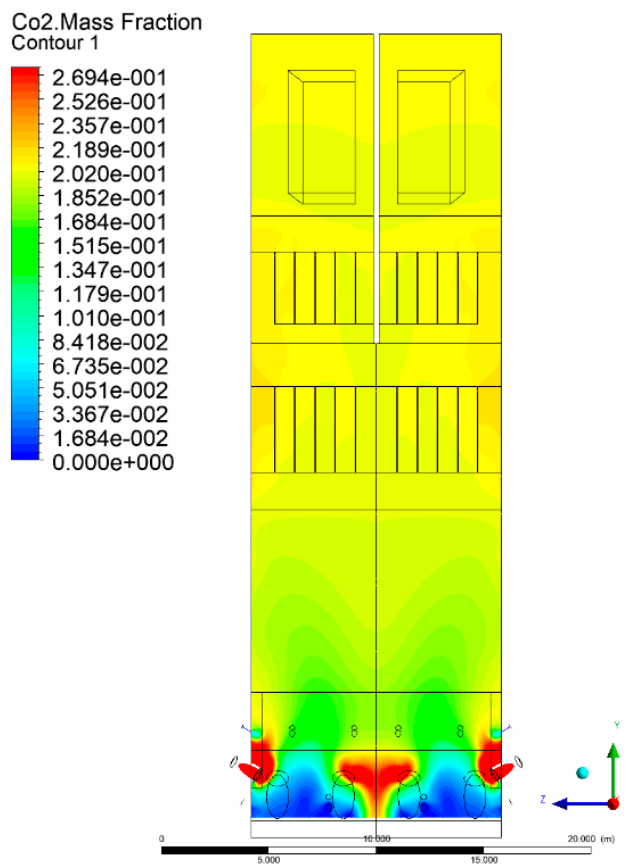

(b)

Figure 34. $\mathrm{CO}_{2}$ concentration in the chamber for sectional view Y-Z-2, (a) Variant K2, (b) Variant K3. 


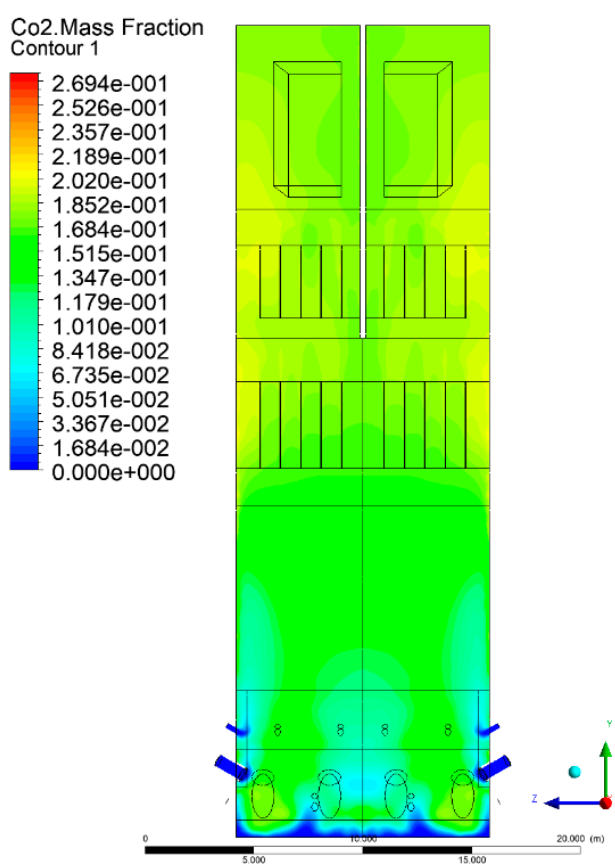

(a)

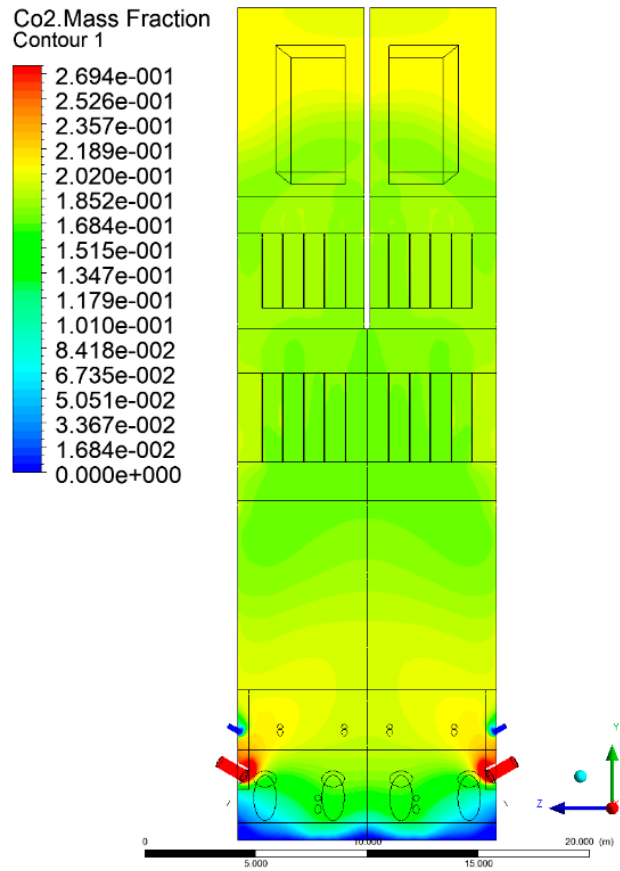

(b)

Figure 35. $\mathrm{CO}_{2}$ concentration in the chamber for sectional view Y-Z-3, (a) Variant K0, (b) Variant K1.

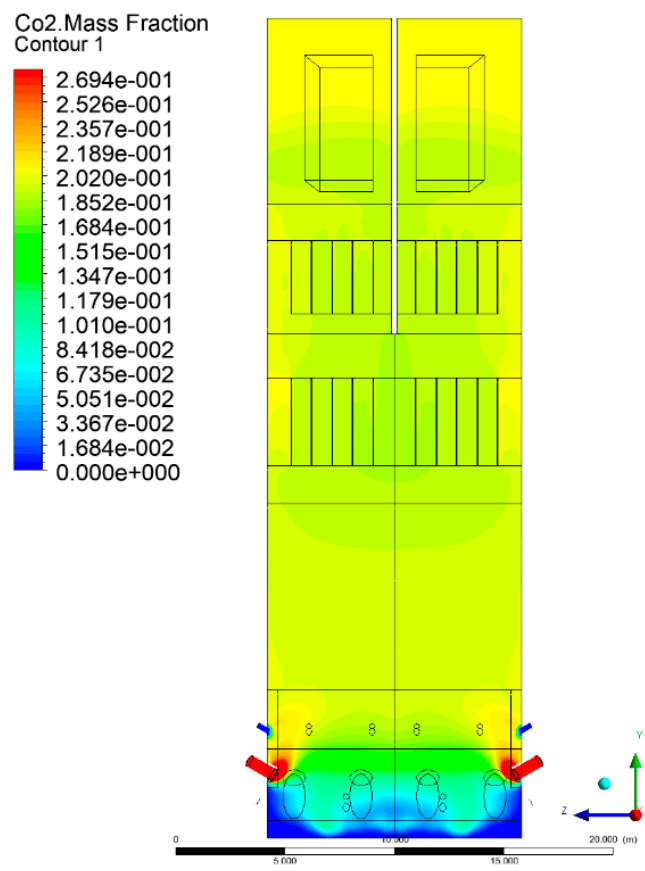

(a)

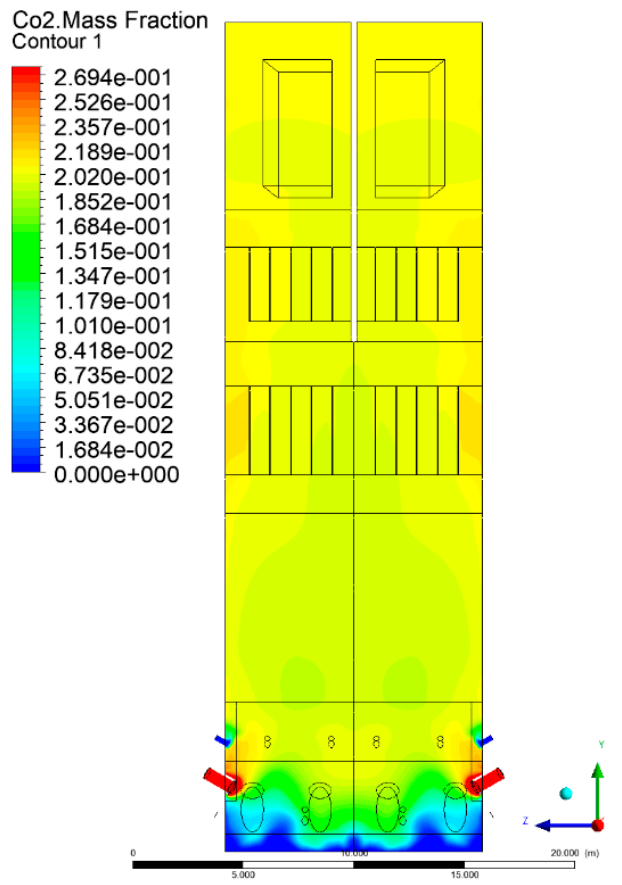

(b)

Figure 36. $\mathrm{CO}_{2}$ concentration in the chamber sectional view Y-Z-3, (a) Variant K2, (b) Variant K3. 


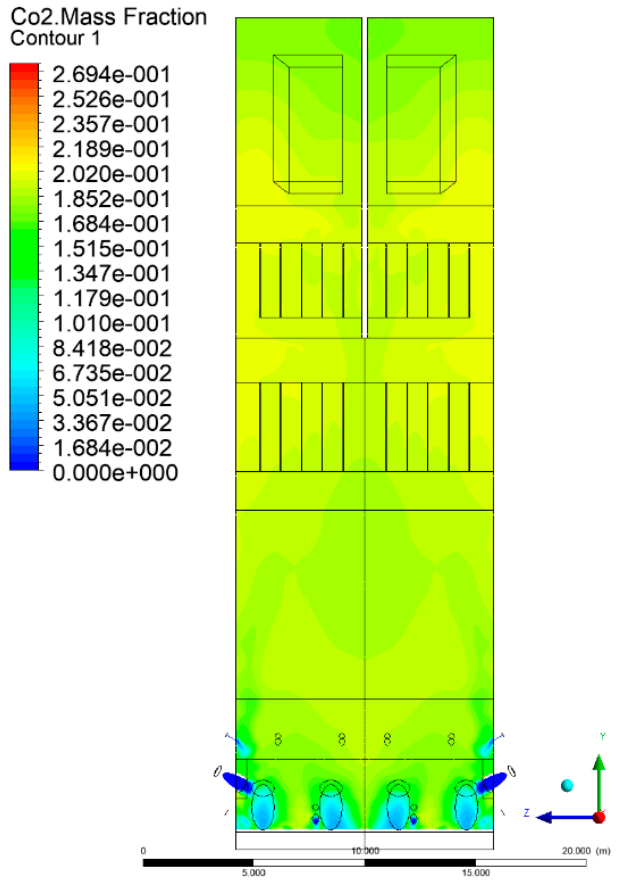

(a)

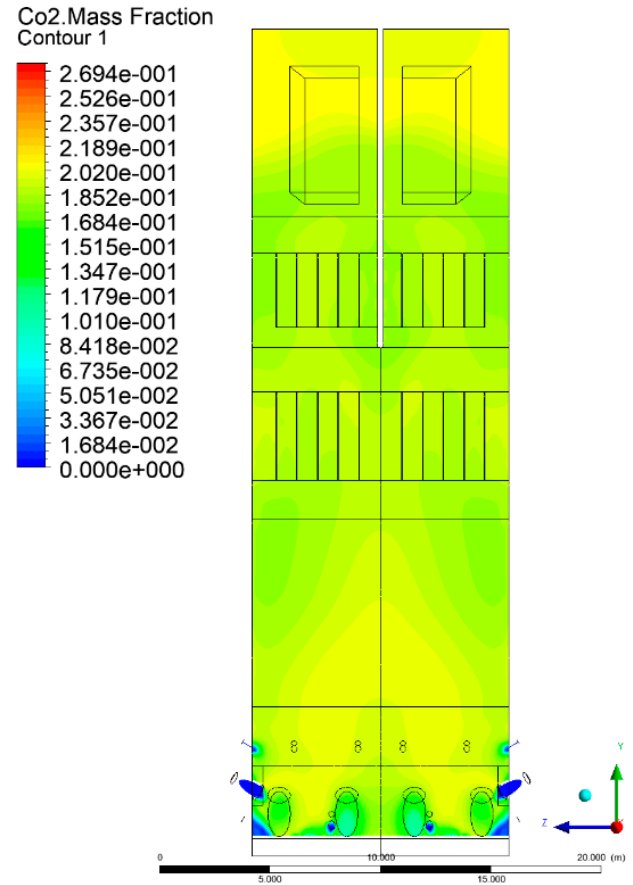

(b)

Figure 37. $\mathrm{CO}_{2}$ concentration in the chamber for sectional view Y-Z-4, (a) Variant K0, (b) Variant K1.

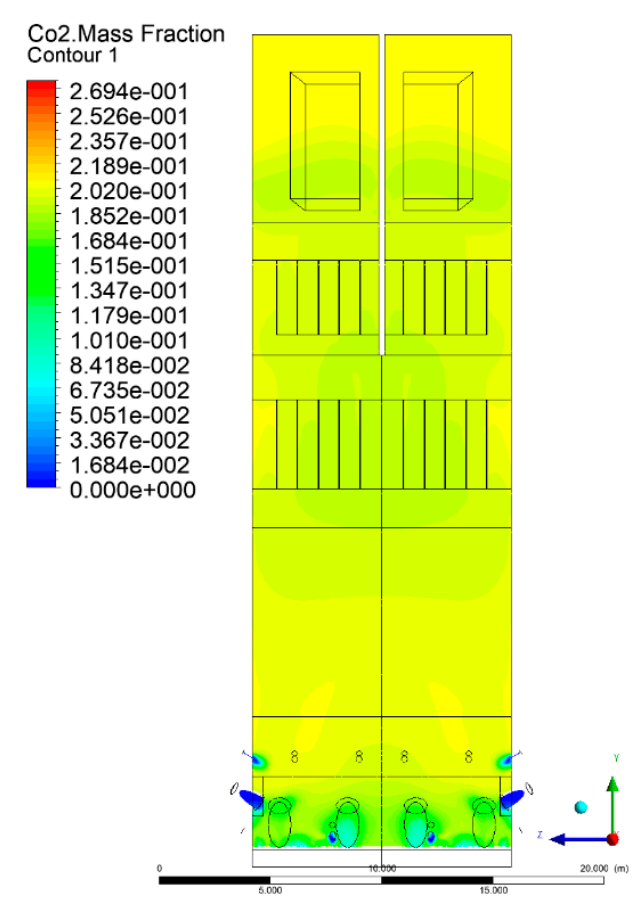

(a)

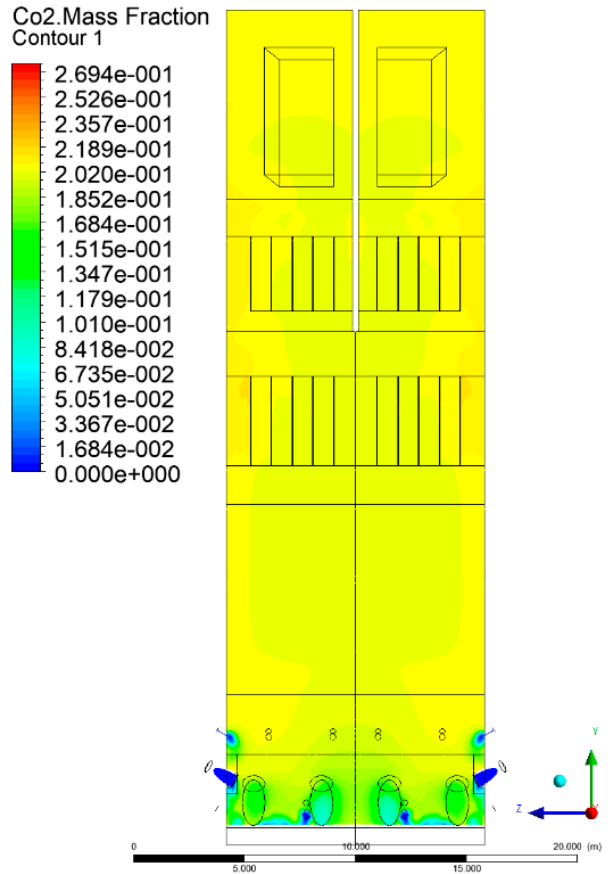

(b)

Figure 38. $\mathrm{CO}_{2}$ concentration in the chamber for sectional view Y-Z-4, (a) Variant K2, (b) Variant K3. 


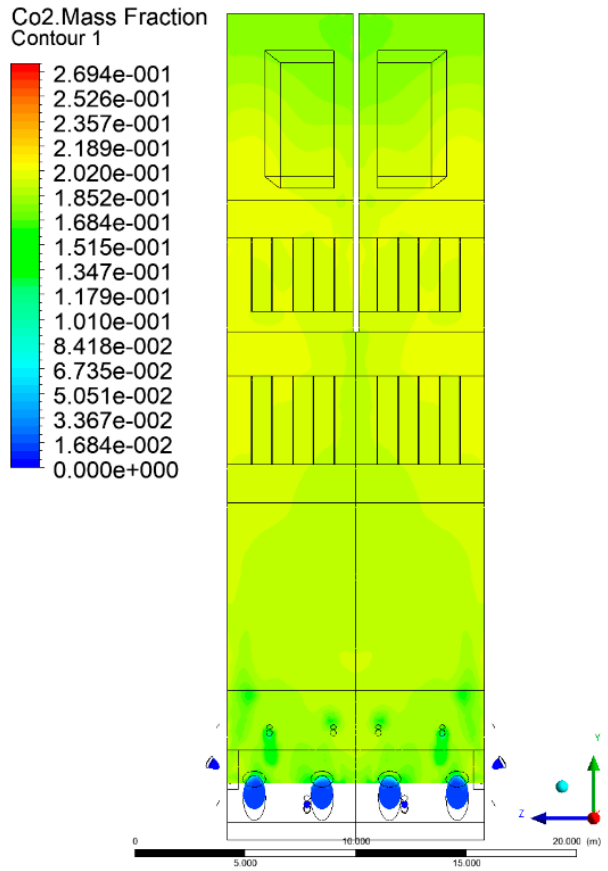

(a)

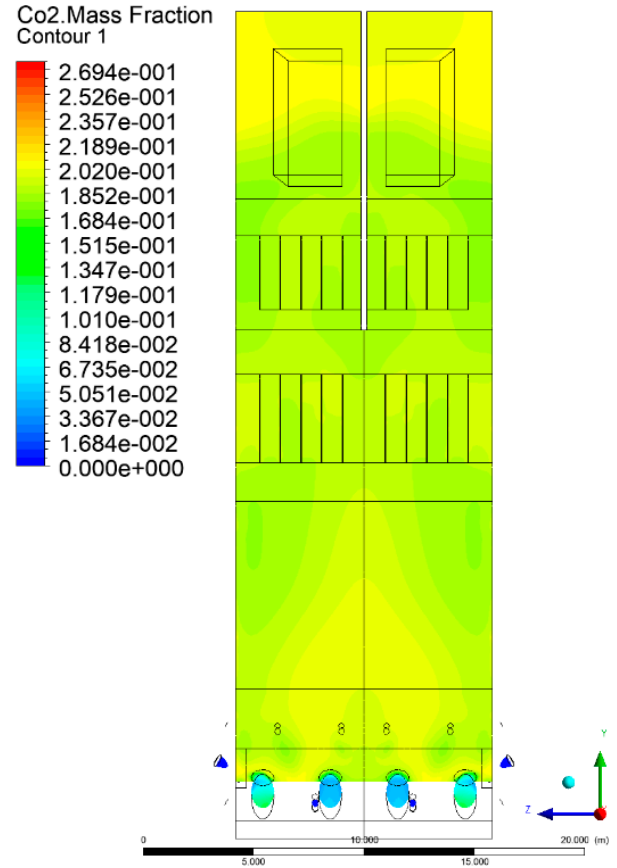

(b)

Figure 39. $\mathrm{CO}_{2}$ concentration in the chamber for sectional view Y-Z-5, (a) Variant K0, (b) Variant K1.

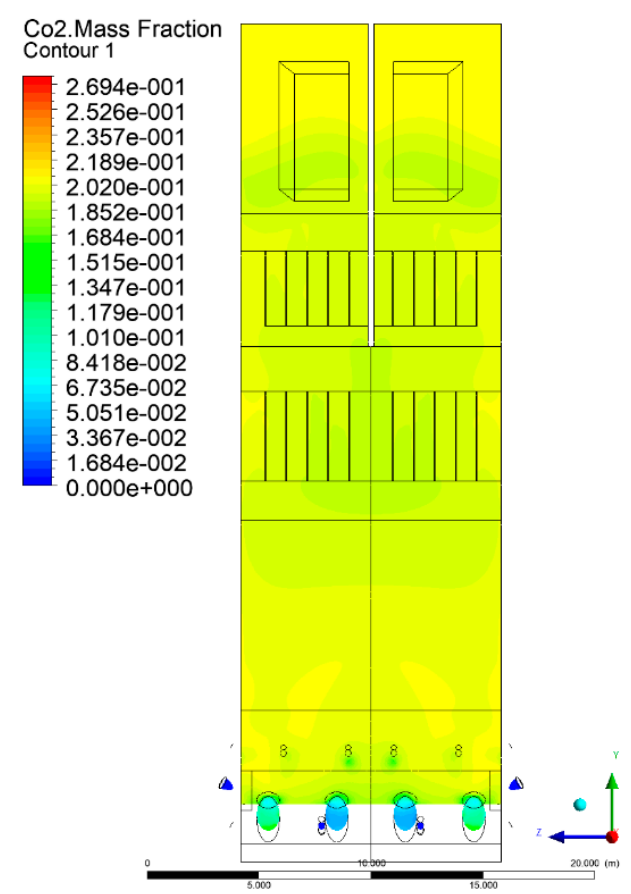

(a)

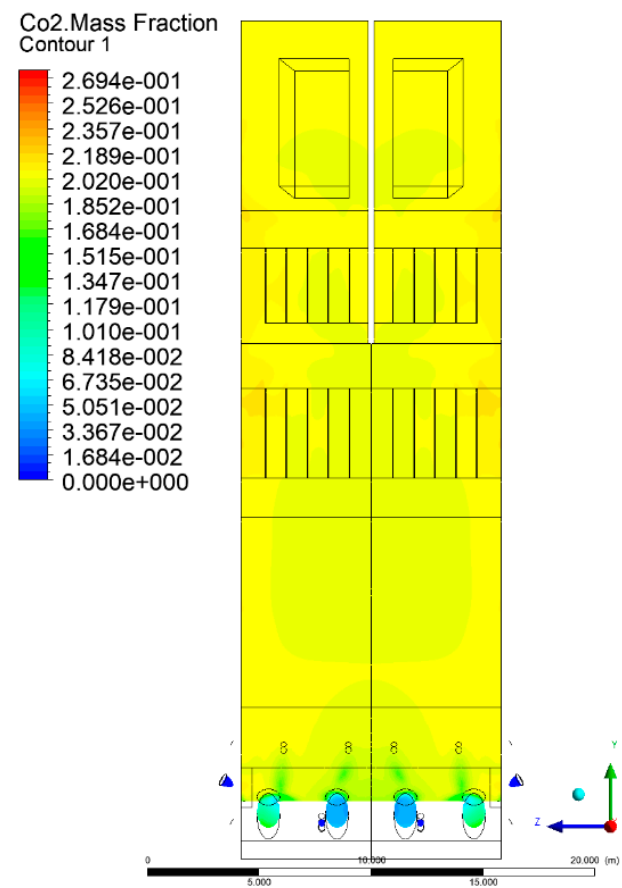

(b)

Figure 40. $\mathrm{CO}_{2}$ concentration in the chamber for sectional view Y-Z-5, (a) Variant K2, (b) Variant K3. 


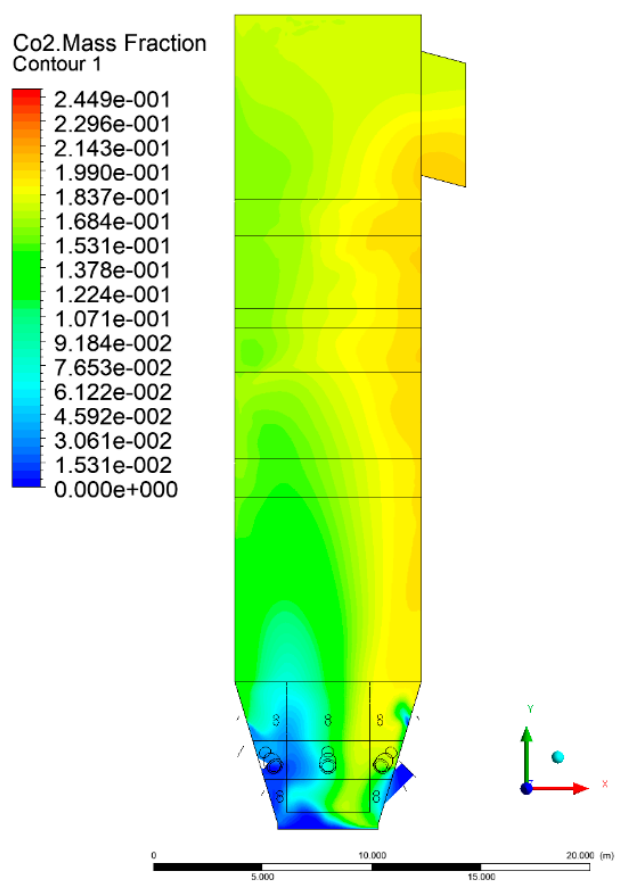

(a)

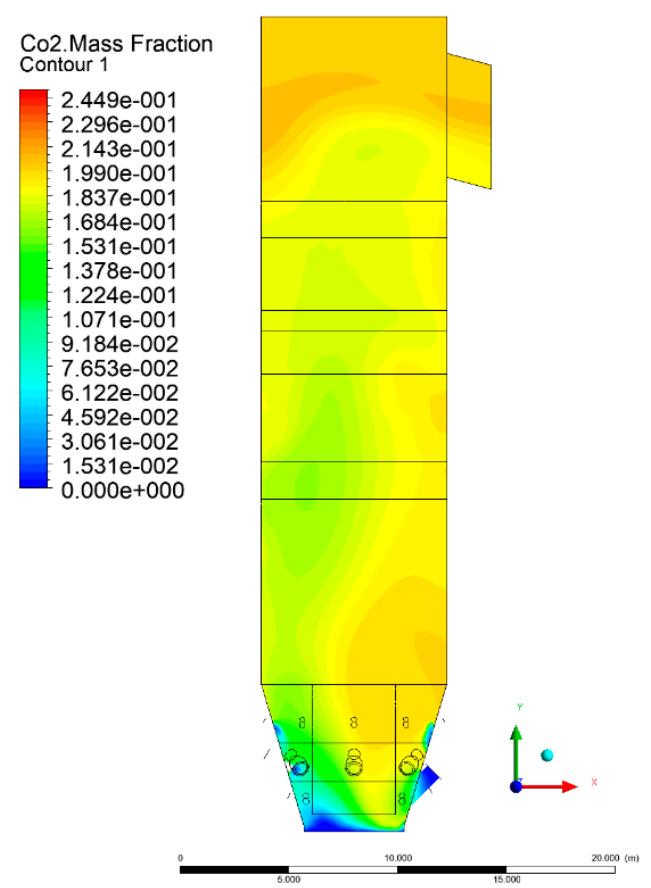

(b)

Figure 41. $\mathrm{CO}_{2}$ concentration in the chamber for sectional view X-Y-1, (a) Variant K0, (b) Variant K1.

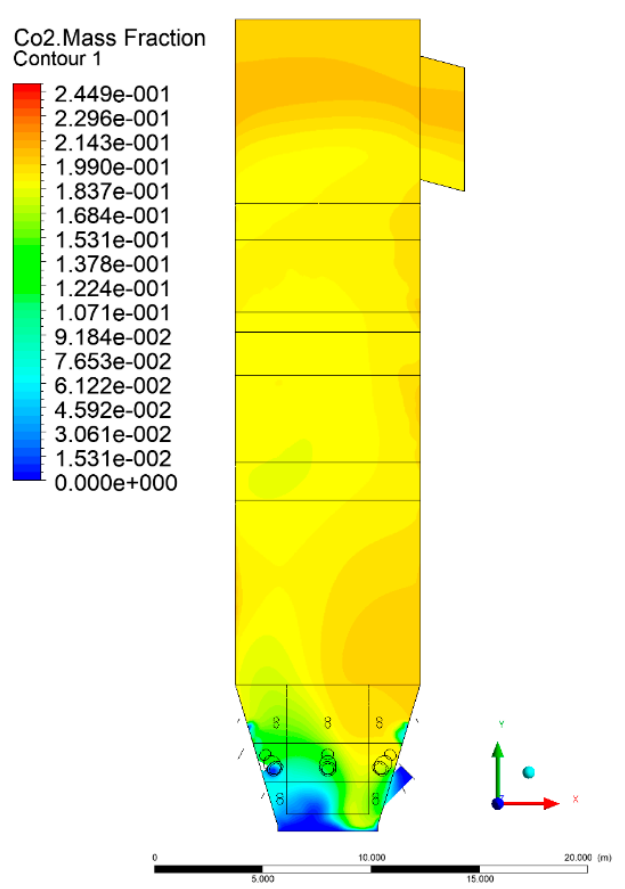

(a)

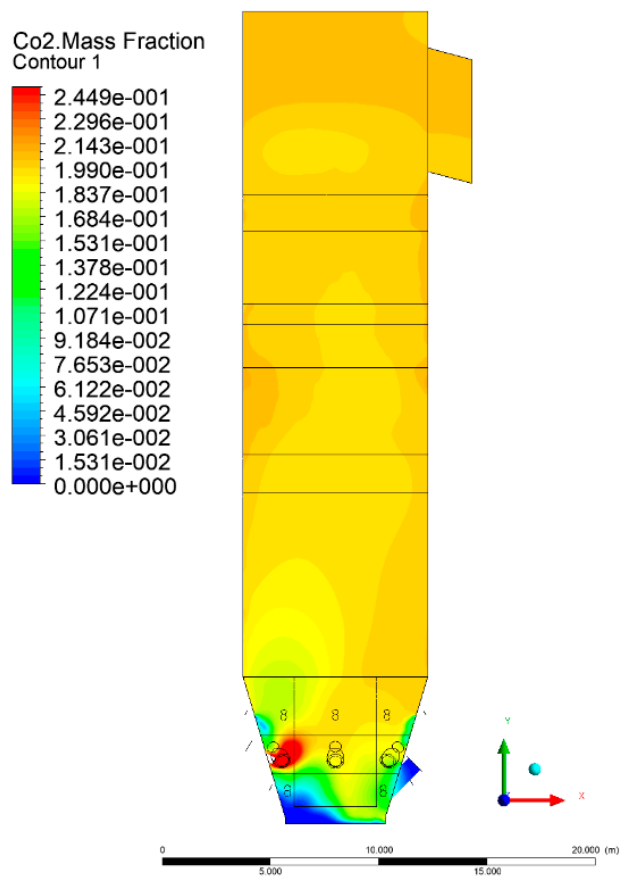

(b)

Figure 42. $\mathrm{CO}_{2}$ concentration in the chamber sectional view $\mathrm{X}-\mathrm{Y}-1$, (a) Variant $\mathrm{K} 2$, (b) Variant K3. 


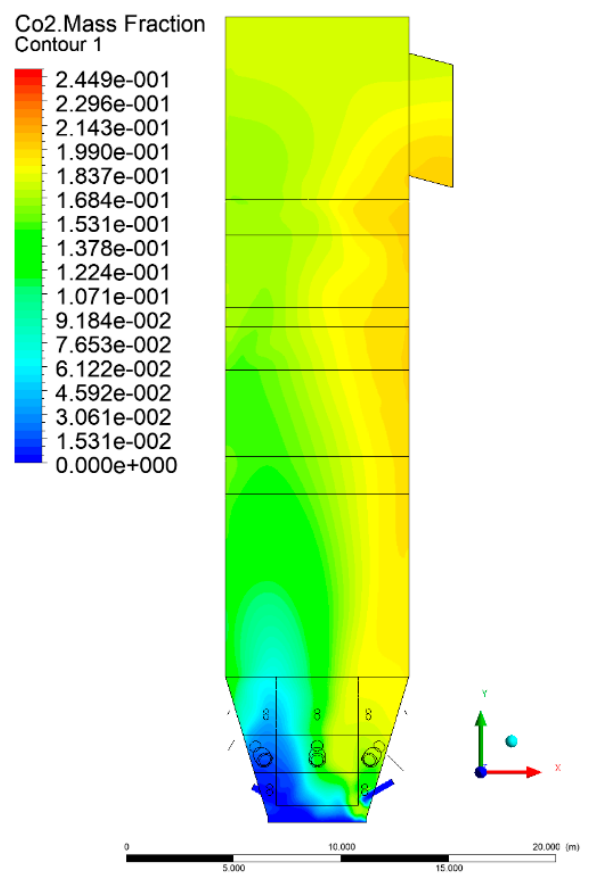

(a)

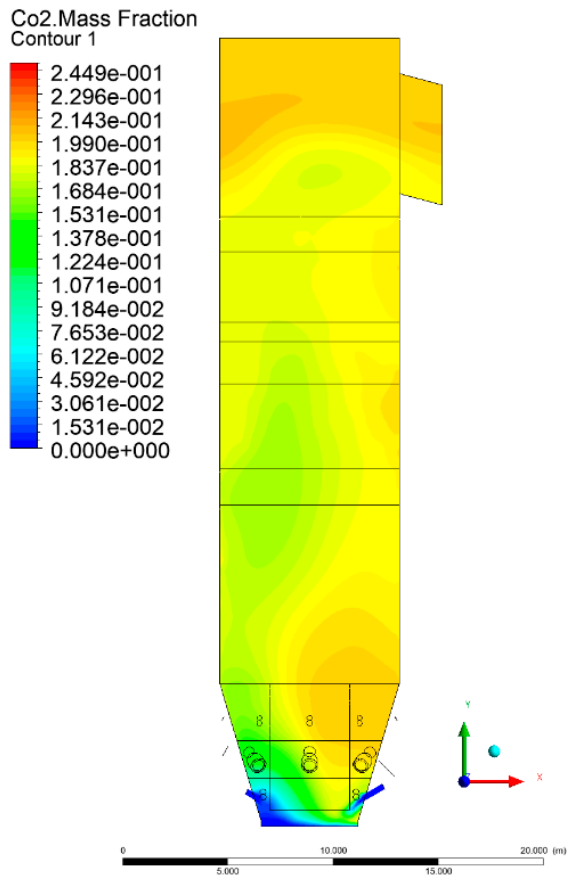

(b)

Figure 43. $\mathrm{CO}_{2}$ concentration in the chamber for sectional view X-Y-2, (a) Variant K0, (b) Variant K1.

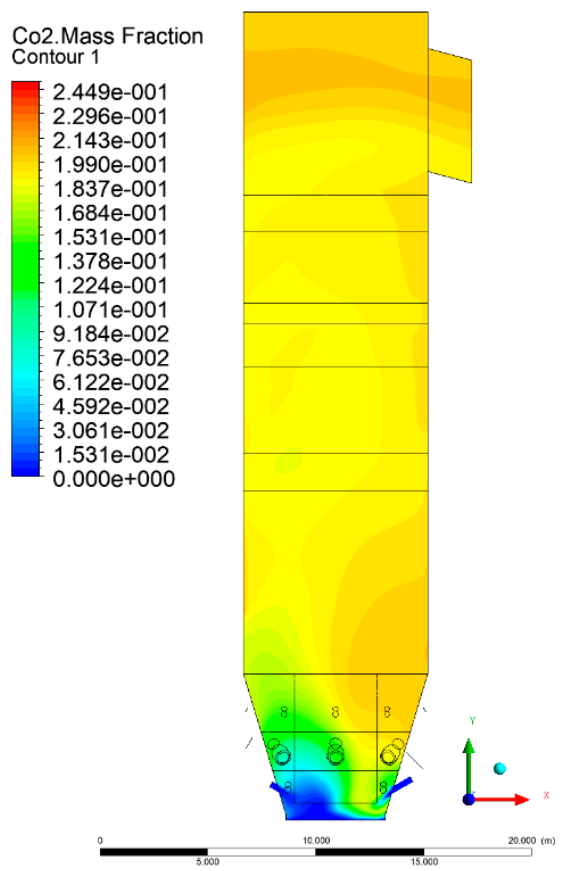

(a)

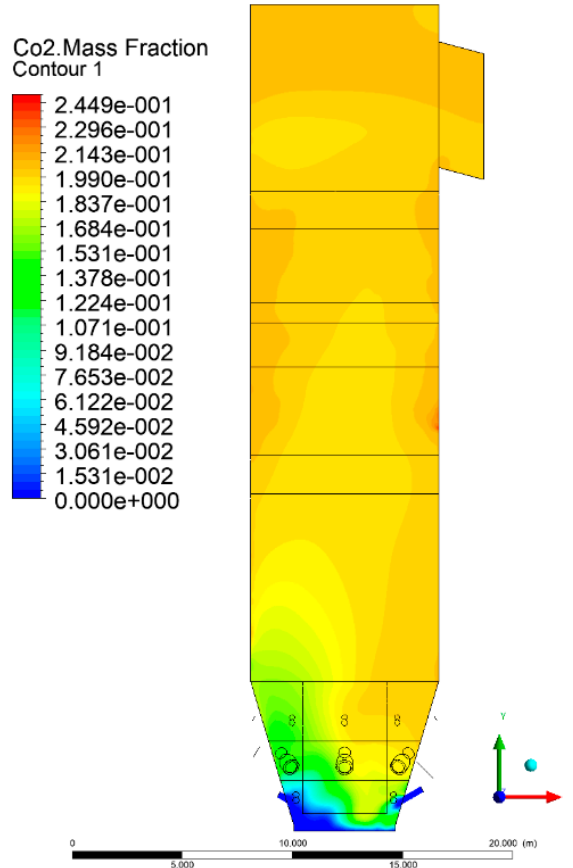

(b)

Figure 44. $\mathrm{CO}_{2}$ concentration in the chamber for sectional view X-Y-2, (a) Variant K2, (b) Variant K3. 


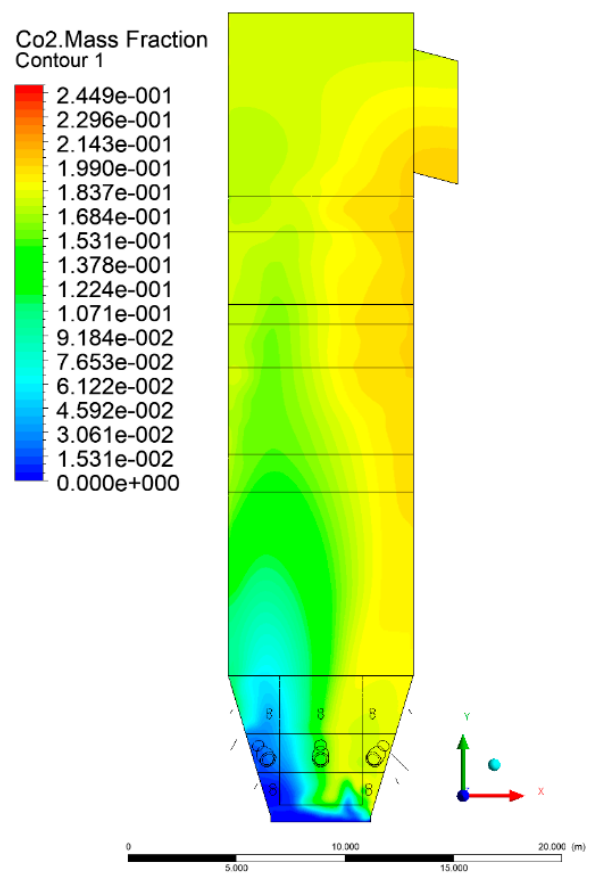

(a)

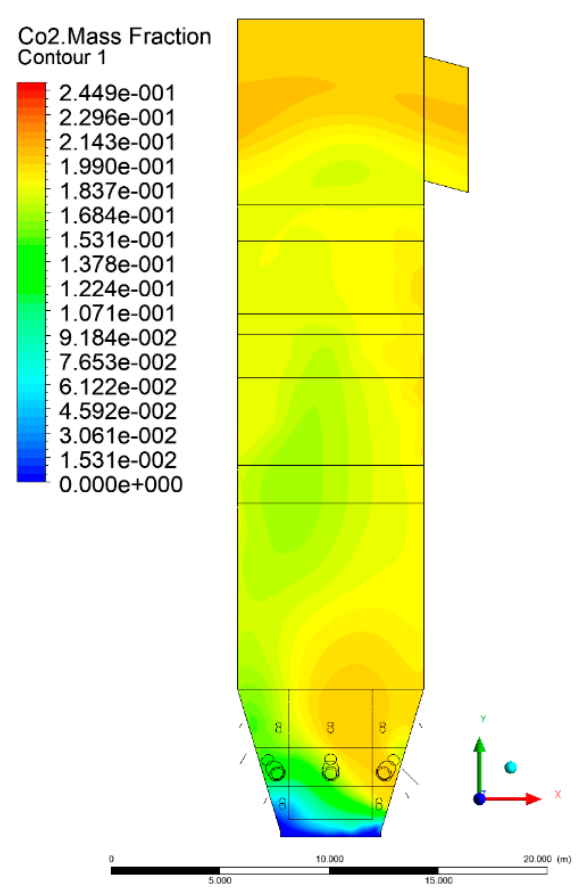

(b)

Figure 45. $\mathrm{CO}_{2}$ concentration in the chamber for sectional view X-Y-3, (a) Variant K0, (b) Variant K1.

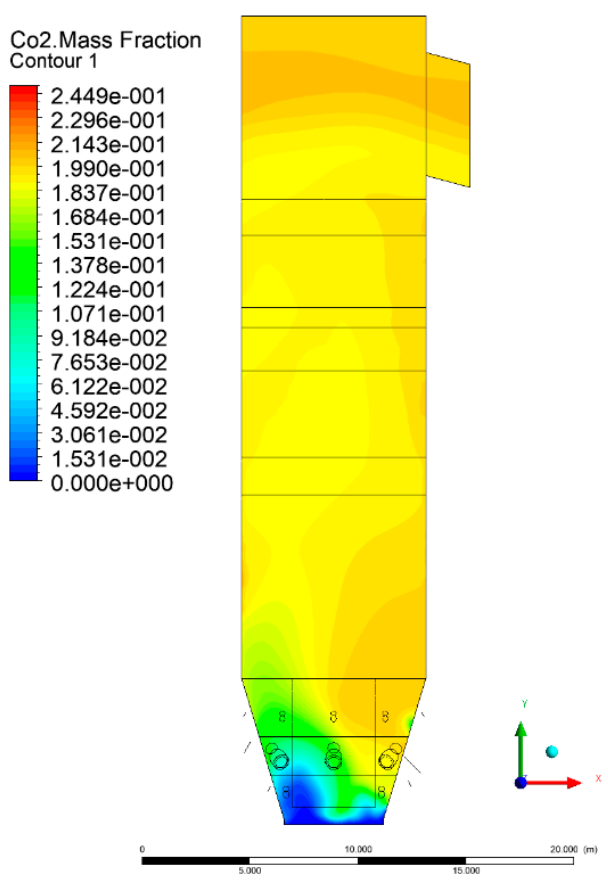

(a)

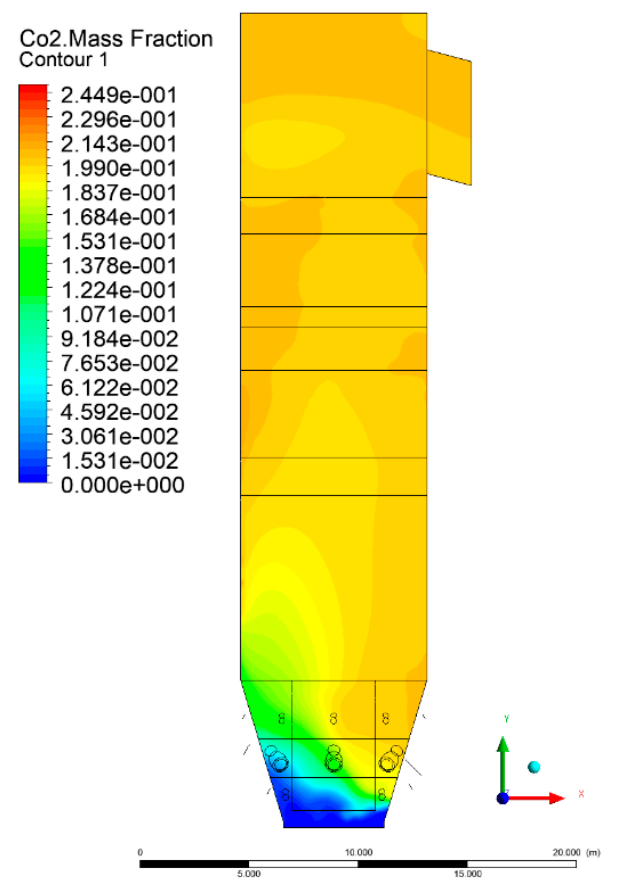

(b)

Figure 46. $\mathrm{CO}_{2}$ concentration in the chamber for sectional view X-Y-3, (a) Variant K2, (b) Variant K3. 


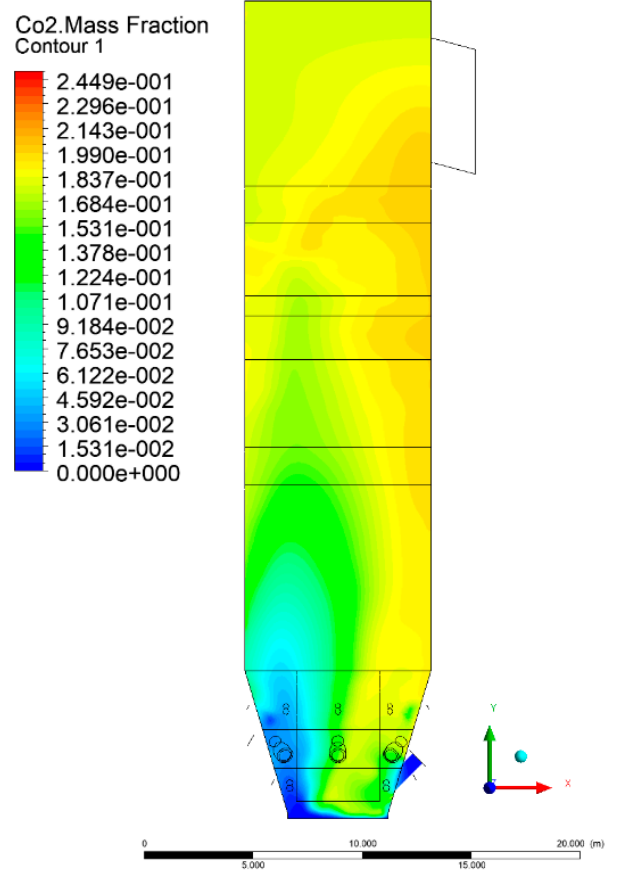

(a)

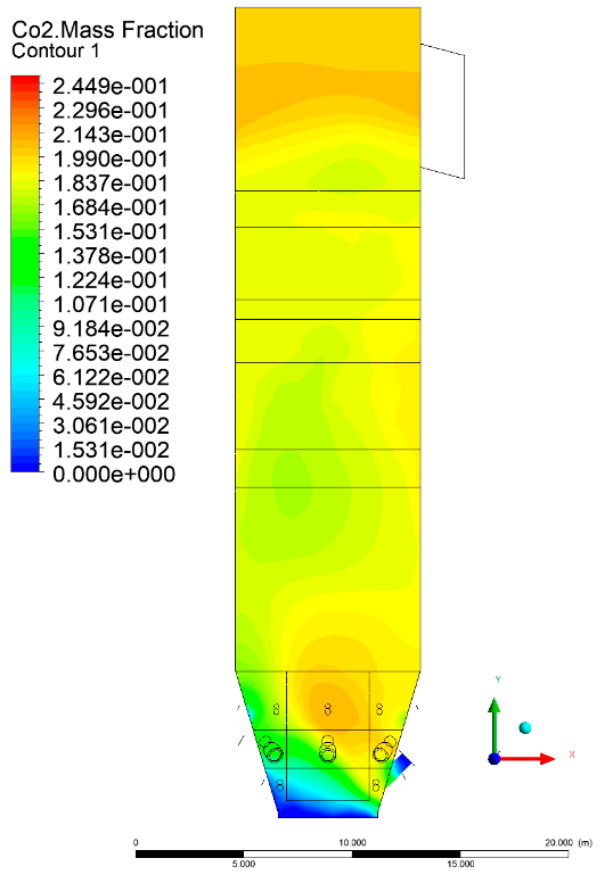

(b)

Figure 47. $\mathrm{CO}_{2}$ concentration in the chamber for sectional view X-Y-4, (a) Variant K0, (b) Variant K1.

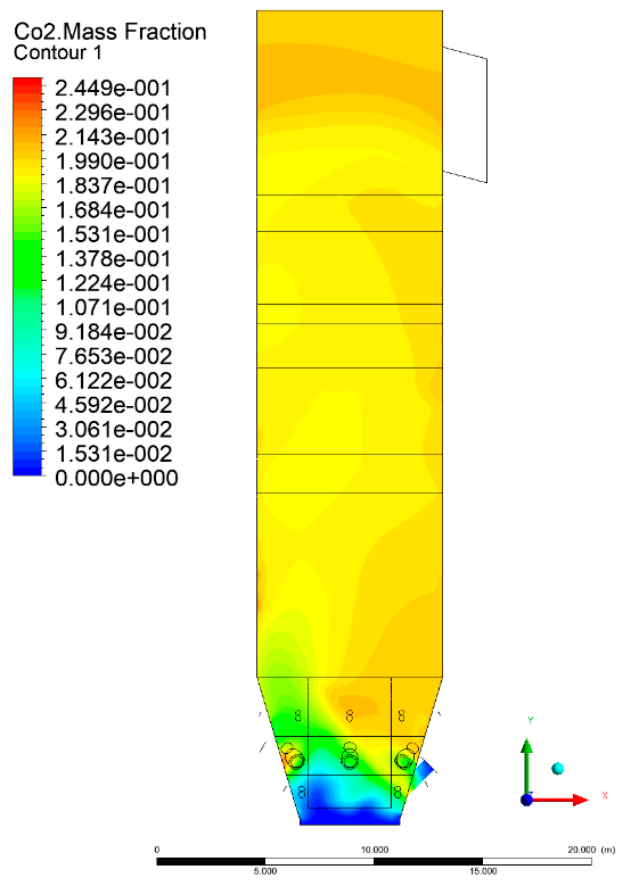

(a)

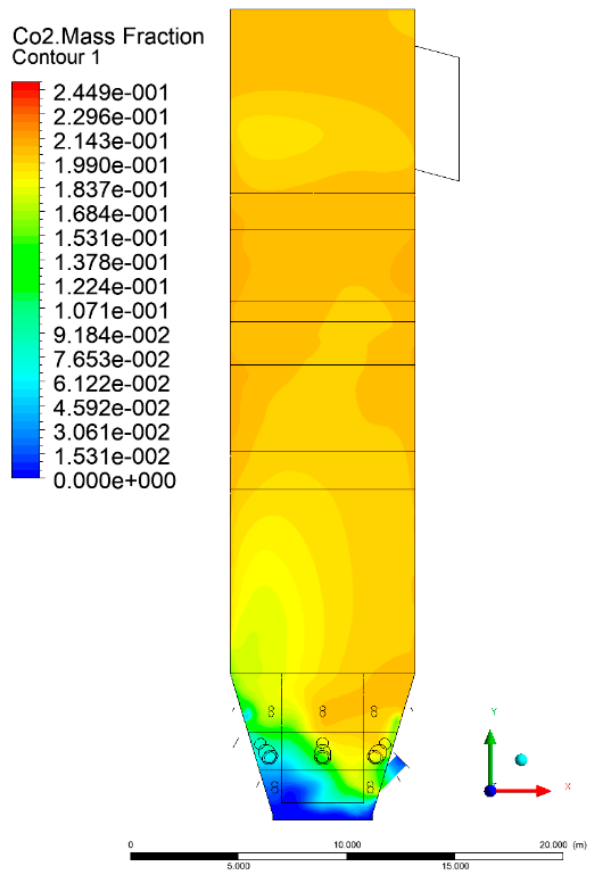

(b)

Figure 48. $\mathrm{CO}_{2}$ concentration in the chamber for sectional view X-Y-4, (a) Variant K2, (b) Variant K3. 


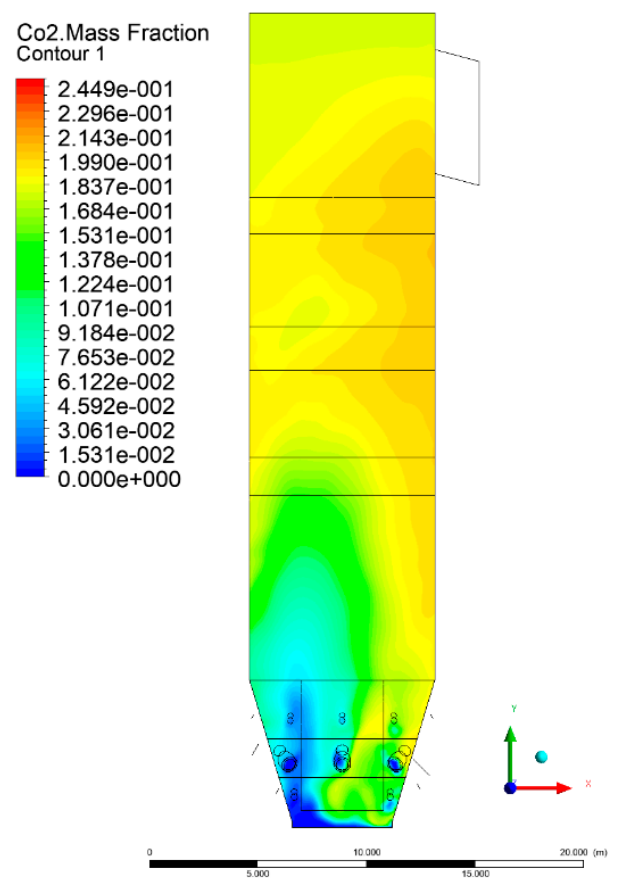

(a)

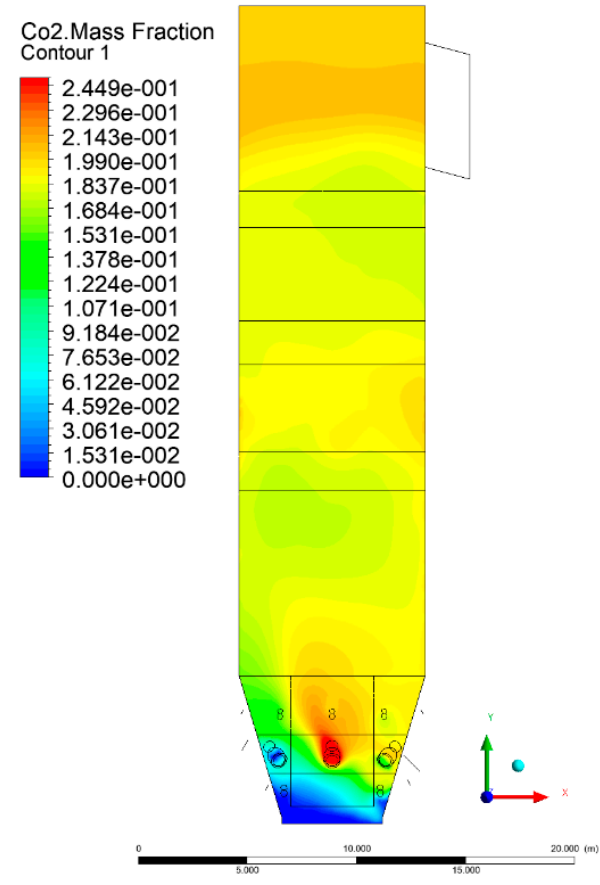

(b)

Figure 49. $\mathrm{CO}_{2}$ concentration in the chamber for sectional view X-Y-5, (a) Variant K0, (b) Variant K1.

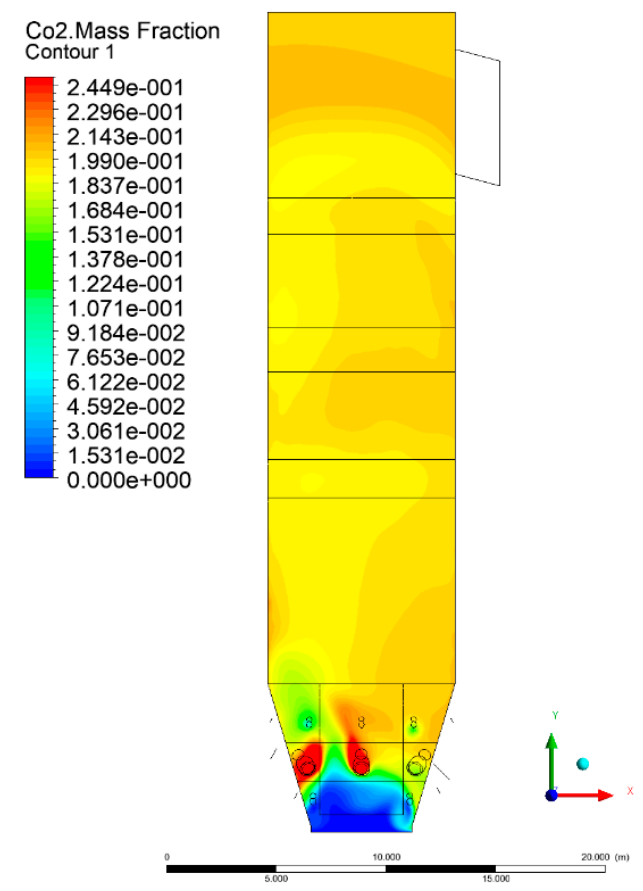

(a)

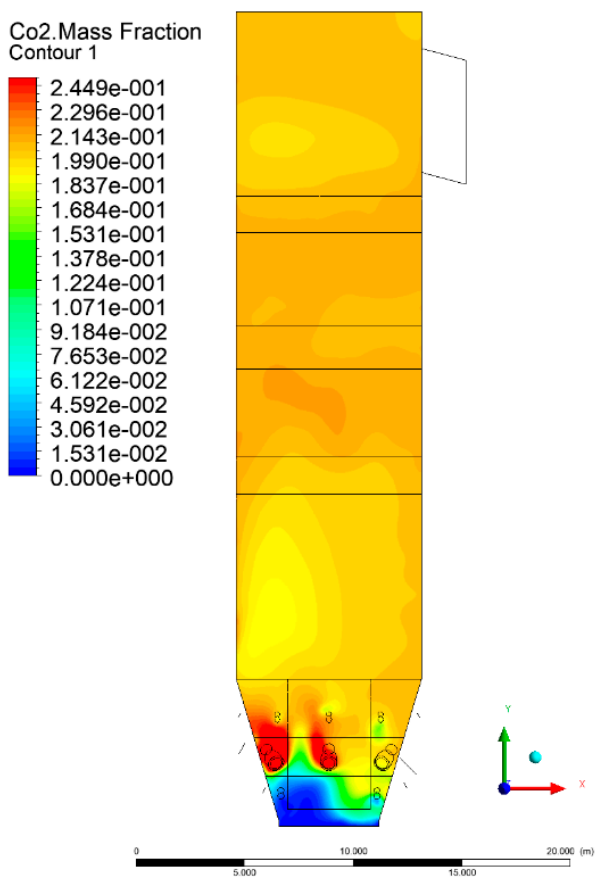

(b)

Figure 50. $\mathrm{CO}_{2}$ concentration in the chamber for sectional view X-Y-5, (a) Variant K2, (b) Variant K3.

The fields of $\mathrm{CO}_{2}$ concentrations in the furnace were closely related to the reactivity zones of the reactants in the calculation domain. Moreover, the fact of the participation of carbon dioxide molecules in the radiation heat transfer mechanism is also noteworthy. Being a compound absorbing radiation, $\mathrm{CO}_{2}$ influenced temperature distributions in the furnace $[30,38,39]$. 


\section{Discussion and Concluding Remarks}

Model research of a large-scale, OFZ-425, CFB boiler was carried out in this paper using a comprehensive 3D-CFD model. Models built using the CFD approach are the most comprehensive, numerically sophisticated, and advanced, based on detailed consideration of chemical kinetics and individual physical processes, gas, and solids continuity equations, momentum balances, and appropriate constitutive equations [2,40]. The purpose of the model was to identify the thermal-flow phenomena occurring in the fluidized bed under its standard operating configuration and modified conditions, i.e., with additional gaseous fuel supply. The influence of the introduced syngas on the distribution of pressures, temperatures, gas flow rate, and $\mathrm{CO}_{2}$ concentrations in the furnace of the $\mathrm{CFB}$ boiler was evaluated. This undertaking emerges from an awareness of the growing environmental pollution and climate change, and it constitutes another attempt to find a method to reduce emissions from fossil fuel combustion [41-43].

In the case of the mono-combustion case, the distribution of pressures inside the furnace was similar to the experimental data. All the discrepancies resulted from the simplifications in the defined hydrodynamic and reactions model. In the reference case $\mathrm{K} 0$, the flow velocity in the bed varied between 4 and $12 \mathrm{~m} / \mathrm{s}$. A significant velocity increase was observed in each of the examined cases in the zones of paten superheaters. The supply of additional syngas to the combustion chamber in Variants $\mathrm{K} 1, \mathrm{~K} 2$, and $\mathrm{K} 3$, did not cause any changes in the pressure distribution and velocities compared to the reference case $\mathrm{K} 0$.

The syngas supply affected $\mathrm{CO}_{2}$ concentration profiles in the furnace. In all considered cases $(\mathrm{K} 1, \mathrm{~K} 2, \mathrm{~K} 3)$, the $\mathrm{CO}_{2}$ concentrations in the combustion chamber increased, not only due to the formation of additional combustion areas, but also via the distribution of $\mathrm{CO}_{2}$ directly from the carbon dioxide-rich gas flowing into the furnace.

For each case (K1, K2, K3), the syngas supply led to an increase in temperature inside the furnace to over $1000{ }^{\circ} \mathrm{C}$, mainly in the lower parts of the combustion chamber. Such a significant increase in temperature may lead to forming agglomerates, which can cause de-fluidization [16].

It is also worth emphasizing that due to the relatively low complexity of the model, the analysis did not cover many additional aspects related to the condition changes in the combustion chamber. The issues of $\mathrm{NO}_{\mathrm{x}}$ emissions directly related to the temperature distribution in the combustion chamber was also essential in the considered cases.

The evaluation carried out in the paper clearly showed that the syngas supply into the furnace chamber of the OFz-425, CFB boiler is not advisable and may lead to frequent emergency stops of the boiler.

Author Contributions: Writing-review and editing, J.K., K.S., M.S., T.S., W.N.; conceptualization and methodology, W.N., K.S., M.S., T.S. software, T.S., M.S.; validation, T.S., M.S., K.S., W.N., formal analysis, K.S., W.N., J.K.; investigation, K.S., T.S., M.S., W.N.; writing—original draft preparation, J.K., K.S., M.S., T.S., W.N.; visualization, T.S., M.S., K.S.; supervision, K.S., W.N.; project administration, W.N.; funding acquisition, Ł.M., W.N., K.S. All authors have read and agreed to the published version of the manuscript.

Funding: This research was funded by a subsidy from the Faculty of Energy and Fuels, AGH University of Science and Technology, No. 16.16.210.476.

Conflicts of Interest: The author declares no conflicts of interest.

\section{References}

1. Cengel, Y.A.; Boles Michael, A. THERMODYNAMICS: An Engineering Approach, 8th ed; McGraw-Hill Education, 2 Penn Plaza: New York, NY, USA, 2015; p. 10121.

2. Krzywanski, J. Heat Transfer Performance in a Superheater of an Industrial CFBC Using Fuzzy Logic-Based Methods. Entropy 2019, 21, 919. [CrossRef]

3. Kotowicz, J.; Brzęczek, M. Comprehensive multivariable analysis of the possibility of an increase in the electrical efficiency of a modern combined cycle power plant with and without a $\mathrm{CO}_{2}$ capture and compression installations study. Energy 2019, 175, 1100-1120. [CrossRef] 
4. Kotowicz, J.; Brzęczek, M. Analysis of increasing efficiency of modern combined cycle power plant: A case study. Energy 2018, 153, 90-99. [CrossRef]

5. Gungor, A.; Eskin, N. Two-dimensional coal combustion modeling of CFB. Int. J. Therm. Sci. 2008, 47, 157-174. [CrossRef]

6. Hupa, M. Interaction of fuels in co-firing in FBC. Fuel 2005, 84, 1312-1319. [CrossRef]

7. Yue, G.; Cai, R.; Lu, J.; Zhang, H. From a CFB reactor to a CFB boiler-The review of R\&D progress of CFB coal combustion technology in China. Powder Technol. 2017, 316, 18-28. [CrossRef]

8. Leckner, B. Co-combustion: A summary of technology. Therm. Sci. 2007, 11, 5-40. [CrossRef]

9. Werther, J. Potentials of Biomass Co-Combustion in Coal-Fired Boilers. In Proceedings of the 20th International Conference on Fluidized Bed Combustion; Yue, G., Zhang, H., Zhao, C., Luo, Z., Eds.; Springer: Berlin/Heidelberg, Germany, 2010; pp. 27-42.

10. Wischnewski, R.; Ratschow, L.; Hartge, E.-U.; Werther, J. Reactive gas-solids flows in large volumes-3D modeling of industrial circulating fluidized bed combustors. Particuology 2010, 8, 67-77. [CrossRef]

11. Knoebig, T.; Luecke, K.; Werther, J. Mixing and reaction in the circulating fluidized bed-A three-dimensional combustor model. Chem. Eng. Sci. 1999, 54, 2151-2160. [CrossRef]

12. Xu, L.; Cheng, L.; Ji, J.; Wang, Q.; Fang, M. A comprehensive CFD combustion model for supercritical CFB boilers. Particuology 2019, 43, 29-37. [CrossRef]

13. Wan, Z.; Yang, S.; Wei, Y.; Hu, J.; Wang, H. CFD modeling of the flow dynamics and gasification in the combustor and gasifier of a dual fluidized bed pilot plant. Energy 2020, 198, 117366. [CrossRef]

14. Liu, Q.; Zhong, W.; Gu, J.; Yu, A. Three-dimensional simulation of the co-firing of coal and biomass in an oxy-fuel fluidized bed. Powder Technol. 2020, 373, 522-534. [CrossRef]

15. Yan, J.; Lu, X.; Xue, R.; Lu, J.; Zheng, Y.; Zhang, Y.; Liu, Z. Validation and application of CPFD model in simulating gas-solid flow and combustion of a supercritical CFB boiler with improved inlet boundary conditions. Fuel Process. Technol. 2020, 208, 106512. [CrossRef]

16. Arjunwadkar, A.; Basu, P.; Acharya, B. A review of some operation and maintenance issues of CFBC boilers. Appl. Therm. Eng. 2016, 102, 672-694. [CrossRef]

17. Taler, J. Thermal and flow processes in large steam boilers. In Modeling and Monitoring; PWN: Warsaw, Poland, 2011.

18. Bis, Z. Fluidized Bed Boilers. Theory and Practice. Czestochowa; University of Technology Press: Czestochowa, Poland, 2010; pp. 215-227.

19. Kruczek, S. Boilers. In Constructions and Calculations; Wroclaw University of Technology: Wroclaw, Poland, 2001.

20. Krzywanski, J.; Żyłka, A.; Czakiert, T.; Kulicki, K.; Jankowska, S.; Nowak, W. A 1.5D model of a complex geometry laboratory scale fuidized bed clc equipment. Powder Technol. 2017, 316, 592-598. [CrossRef]

21. Muskała, W.; Krzywański, J.; Rajczyk, R.; Cecerko, M.; Kierzkowski, B.; Nowak, W.; Gajewski, W. Investigation of erosion in CFB boilers. Rynek Energii 2010, 87, 97-102.

22. Krzywanski, J.; Wesolowska, M.; Blaszczuk, A.; Majchrzak, A.; Komorowski, M.; Nowak, W. Fuzzy logic and bed-to-wall heat transfer in a large-scale CFBC. Int. J. Numer. Methods Heat Fluid Flow 2018, 28, 254-266. [CrossRef]

23. Sosnowski, M.; Krzywanski, J.; Scurek, R. A Fuzzy Logic Approach for the Reduction of MeshInduced Error in CFD Analysis: A Case Study of an Impinging Jet. Entropy 2019, 21, 1047. [CrossRef]

24. Grabowska, K.; Sosnowski, M.; Krzywanski, J.; Sztekler, K.; Kalawa, W.; Zylka, A.; Nowak, W. The Numerical Comparison of Heat Transfer in a Coated and Fixed Bed of an Adsorption Chiller. J. Therm. Sci. 2018, 27, 421-426. [CrossRef]

25. Versteeg, H.K.; Malalasekera, W. An Introduction to Computational Fluid Dynamics: The Finite Volume Method; Pearson Education: London, UK, 2007; ISBN 978-0-13-127498-3.

26. ANSYS, Inc. Ansys Fluent Theory Guide; ANSYS Inc.: Canonsburg, PA, USA, 2013.

27. Zhou, W.; Zhao, C.; Duan, L.; Chen, X.; Liu, D. A simulation study of coal combustion under $\mathrm{O}_{2} / \mathrm{CO}_{2}$ and O2/RFG atmospheres in circulating fluidized bed. Chem. Eng. J. 2013, 223, 816-823. [CrossRef]

28. Muskała, W.; Krzywański, J.; Czakiert, T.; Nowak, W. The research of CFB boiler operation for oxygen-enhanced dried lignite combustion. Rynek Energii 2011, 1, 172-176.

29. Muskała, W.; Krzywański, J.; Sekret, R.; Nowak, W. Model research of coal combustion in circulating fluidized bed boilers. Chem. Process Eng. 2008, 29, 473-492. 
30. Basu, P. Circulating Fluidized Bed Boilers: Design, Operation and Maintenance; Springer: Berlin/Heidelberger, Germany, 2015; ISBN 978-3-319-06172-6.

31. Basu, P. Combustion and Gasification in Fluidized Beds; CRC Press: New York, NY, USA, 2006; ISBN 978-1-4200-0515-8.

32. Chen, Z.; Lin, M.; Ignowski, J.; Kelly, B.; Linjewile, T.M.; Agarwal, P.K. Mathematical modeling of fluidized bed combustion. 4: $\mathrm{N}_{2} \mathrm{O}$ and $\mathrm{NO}_{X}$ emissions from the combustion of char. Fuel 2001, 80, 1259-1272. [CrossRef]

33. Krzywanski, J.; Czakiert, T.; Shimizu, T.; Majchrzak-Kuceba, I.; Shimazaki, Y.; Zylka, A.; Grabowska, K.; Sosnowski, M. NOx Emissions from Regenerator of Calcium Looping Process. Energy Fuels 2018, 32, 6355-6362. [CrossRef]

34. Miller, J.A.; Bowman, C.T. Mechanism and modeling of nitrogen chemistry in combustion. Prog. Energy Combust. Sci. 1989, 15, 287-338. [CrossRef]

35. Hayhurst, A.N.; Lawrence, A.D. The amounts of $\mathrm{NO}_{\mathrm{x}}$ and $\mathrm{N}_{2} \mathrm{O}$ formed in a fluidized bed combustor during the burning of coal volatiles and also of char. Combust. Flame 1996, 105, 341-357. [CrossRef]

36. Klajny, T.; Krzywanski, J.; Nowak, W. Mechanism and kinetics of coal combustion in oxygen enhanced conditions. In Proceedings of the 6th Internationa Symposium on Coal Combustion. Huazhong University of Science and Technology, Wuhan, China, 1-4 December 2007; pp. 148-153.

37. Lehtonen, P.; Stroemdahl, J. CFB. Multi-fuel design features and operating experience ETDEWEB. VGB PowerTech 2012, 92, 40.

38. Yang, W.-C. Handbook of Fluidization and Fluid-Particle Systems; CRC Press: Basel, Switzerland, 2003; ISBN 978-0-8247-4836-4.

39. Breitholtz, C.; Leckner, B.; Baskakov, A.P. Wall average heat transfer in CFB boilers. Powder Technol. 2001, 120, 41-48. [CrossRef]

40. Krzywanski, J. A General Approach in Optimization of Heat Exchangers by Bio-Inspired Artificial Intelligence Methods. Energies 2019, 12, 4441. [CrossRef]

41. Mehmet, K.; Cengel, Y.A.; Cimbala, J.M. Fundamentals and Applications of Renewable Energy; Mac Graw Hill: New York, USA, 2019.

42. Basu, P. Biomass Gasification, Pyrolysis and Torrefaction. Practical Design and Theory; II; Elsevier: San Diego, CA, USA, 2013.

43. Grabowska, K.; Krzywanski, J.; Nowak, W.; Wesolowska, M. Construction of an innovative adsorbent bed configuration in the adsorption chiller-Selection criteria for effective sorbent-glue pair. Energy 2018, 151, 317-323. [CrossRef]

(C) 2020 by the authors. Licensee MDPI, Basel, Switzerland. This article is an open access article distributed under the terms and conditions of the Creative Commons Attribution (CC BY) license (http://creativecommons.org/licenses/by/4.0/). 